\title{
How to decide and visualize whether uncertainty or variability is dominating in Life Cycle Assessment results: a systematic review
}

Freya Michiels $^{1}$ ( $\left.\underline{\text { ORCID }}\right)$, Annemie Geeraerd ${ }^{1,2}(\underline{\text { ORCID }})$

\author{
${ }^{1}$ Sustainability in the Agri-Food Chain Group, MeBioS, Department of Biosystems, KU Leuven, Willem de Croylaan 42, \\ 3001 Leuven, Belgium \\ 22Ethics@ Arenberg, Science, Engineering and Technology Group, KU Leuven, Willem de Croylaan 42, 3001 Leuven, \\ Belgium \\ Corresponding author: Annemie Geeraerd; +32 163205 91; annemie.geeraerd@ kuleuven.be; Willem de Croylaan 42 - bus \\ 2428, 3001 Leuven, Belgium
}

\section{Highlights}

- Data used in Life Cycle Assessments are uncertain and variable

- We reviewed used methodologies to assess uncertainty and variability separately

- Monte Carlo simulations visualized in ratios allows to decide which is dominating

- Global sensitivity analysis allows this through visualizing essential parameters

\section{Abstract}

LCA results are typically reported as deterministic, while reality is uncertain and variable. Through a systematic review, we studied which methodologies and associated visualizations have already been used to assess both uncertainty and variability, as separate concepts, in the same LCA study. We aim to select the most appropriate one(s) that allow to decide whether uncertainty or variability is dominating in the results.

562 studies were identified by combining four topics (uncertainty, variability, LCA and methodology) of which eleven were eligible. These studies used a multi-step approach, often combining Monte Carlo simulations with a local and/or global sensitivity analysis and statistical measures.

Based on our review, we recommend Monte Carlo simulations visualized in uncertainty and variability ratios and global sensitivity analysis visualized using total sensitivity indices for future use in LCA. Ratios allow to clearly decide whether uncertainty or variability is dominating and sensitivity indices allow to identify essential parameters.

\section{Keywords}

Methodology; Uncertainty; Variability; Life Cycle Assessment; Monte Carlo simulation; Sensitivity 


\section{Introduction}

Proper uncertainty reporting is becoming more and more important in different research fields. Finding a straightforward and transferable methodology for that purpose can be challenging, especially since there are different viewpoints regarding the sources and classification of uncertainty. Additionally, variability is often not accounted for or even acknowledged, causing valuable information for stakeholders and decisions makers to be lost.

Walker et al. (2003) distinguished between three dimensions of uncertainty. The first one, location of uncertainty, deals with where the uncertainty is located within the whole model complex (e.g., context, model and inputs). The second dimension was defined as the level of uncertainty, which expresses the degree of which something is known (from deterministic to total ignorance). The third dimension is the nature of uncertainty - and is the main focus of this systematic review - which focusses on how uncertainty relates with reality and more importantly, which strategy we can use to deal with it.

By looking at the nature of uncertainty, a distinction can be made between epistemic uncertainty and variability uncertainty (Walker et al., 2003). Epistemic uncertainty reflects the imperfection of our knowledge (Walker et al., 2003), i.e. "everything we do not know" (Hauschild et al., 2018). This includes systematic or random measurement errors, lack of data, outdated information, subjective judgement, etc. (Hauschild et al., 2018; Walker et al., 2003). Therefore, epistemic uncertainty can be reduced by gaining more knowledge through research (e.g., further measurement, literature research or consulting more experts) (Hauschild et al., 2018; Huijbregts, 1998; Igos et al., 2018; Walker et al., 2003).

In contrast, variability [also called "aleatory" or "ontic" uncertainty (Igos et al., 2018; Walker et al., 2003)] stems from inherent variations in the natural world (Hauschild et al., 2018; Huijbregts, 1998; Igos et al., 2018; Walker et al., 2003), leading to a spread in the data that will always be observed (Hauschild et al., 2018). Therefore, it cannot be reduced through further study (Hauschild et al., 2018; Igos et al., 2018). As Warmink et al. (2010) mention, the distinction between epistemic uncertainty and variability is not always very clear. One can argue that random variation in the natural world can also be seen as a lack of knowledge, which in turn can be reduced given enough resources. However, it is unrealistic to assume unlimited available resources and variability is therefore seen as a variety of system behaviors taking into account a realistic amount of available resources.

Life cycle assessment (LCA) is one of the research fields in which proper uncertainty reporting is becoming more and more important. LCA addresses the potential environmental impacts (e.g., environmental consequences of resource use) throughout a product's life cycle, from raw material to final disposal. LCA outcomes should ensure that impacts are addressed at the point in the life cycle 
where they will most effectively reduce overall environmental impact and resource use (ISO, 2006a). ISO 14040/44 (2006a, 2006b) developed an LCA framework with four iterative phases: Goal \& Scope Definition (defining the functional unit, system boundaries, etc.); Life Cycle Inventory (collecting relevant data with regard to the studied system); Life Cycle Impact Assessment [evaluating potential environmental impacts associated with the in- and outputs by classifying them into specific impact categories, e.g., climate change ( $\mathrm{kg} \mathrm{CO}_{2}$ eq)]; and Life Cycle Interpretation.

Next to this framework, ISO 14040/44 (2006a, 2006b) also lists data quality requirements that should be addressed in an LCA. However, LCA results are still typically being reported as deterministic [e.g., Bosona and Gebresenbet (2018) and Hajibabaei et al. (2018)]. Other studies do include an uncertainty analysis, but completely disregard the distinction between uncertainty and variability [e.g., Bautista et al. (2018) and Jiao et al. (2019)]. Data quality reporting is important to assess the reliability of the study results and to properly understand its outcome (ISO, 2006b). However, uncertainty is frequently used as a very broad concept, often including related concepts such as variability (Hauschild et al., 2018). This makes it difficult for LCA practitioners to clearly define and propagate uncertainty and variability in their analysis. Moreover, uncertainty and variability are often mentioned as factors complicating the interpretation of LCA outcomes (Huijbregts, 1998).

Huijbregts (1998) developed a classification system specifically for LCA to distinguish between different sources of uncertainty and variability, to which Björklund (2002) and Hauschild et al. (2018) extended upon. Huijbregts (1998) distinguished between six types of uncertainty and variability:

1. parameter uncertainty, uncertainty due to a lack of knowledge of the "true" data (e.g., inaccuracy, unrepresentativeness and lack of data),

2. model uncertainty, uncertainty due to a loss of information when modelling reality within the present LCA structure (e.g., assumption of linear relationships),

3. uncertainty due to choices, uncertainty caused by unavoidable choices when performing LCAs (e.g., definition of functional unit),

4. temporal variability, variations over time (e.g., seasons),

5. spatial variability, variations across locations (e.g., regional differences in emission factors), and

6. variability between sources and objects, inherent differences in a product system (e.g., different characteristics between factories).

Björklund (2002) added:

7. epistemological uncertainty, uncertainty caused by lack of knowledge on system behavior (e.g., ignorance about relevant aspects of the studied system), and

8. mistakes (e.g., using wrong units)

to which Hauschild et al. (2018) added: 
9. relevance uncertainty, uncertainty of the representativeness of the used indicators for the decision at hand (e.g., completeness of relevant impact categories covered).

Hauschild et al. (2018) stated that these nine types are essentially sub-classes of a wider used classification of uncertainty i.e., parameter, model and scenario uncertainty. In that case, parameter uncertainty consists of both uncertainty and variability in the model input parameters, and is the most accessible type (though, not necessarily the most important one) to be assessed and addressed in LCA (Hauschild et al., 2018).

Thus, there are different viewpoints when it comes to classifying uncertainty (epistemic and aleatory), which are related to each other, but not completely compatible. Now, turning to the topic of this research paper, the classification as defined by Huijbregts (1998) is used because when dealing with uncertainty and variability in LCA, this classification is often referred to (as of August 5, 2020, Huijbregts's article (1998) has been cited 275 times). To be able to compare the different methodologies, we look at the different viewpoints from the perspective of Huijbregts' classification (1998), without trying to reconcile them or develop a new overarching school of thought.

In this study, the focus lies specifically on methodologies used to propagate 'parameter uncertainty' and 'variability between objects and sources' - as defined by Huijbregts (1998) - because those two types of uncertainty and variability are the most feasible to be quantified in the inventory analysis by the LCA practitioner (Huijbregts, 1998).

Through a systematic review, we aim to study which methodologies have already been used that allow to decide whether uncertainty or variability is dominating in LCA results. Quantifying uncertainty and variability separately in the same LCA study leads to the ability of distinguishing between them in the interpretation phase and making well-informed conclusions and decisions. A systematic review is a review that uses systematic and explicit methods to identify, select, and critically appraise relevant research to answer a clearly formulated research question, with the goal of minimizing bias (Moher et al., 2009).

There have been studies that surveyed (e.g., Lloyd and Ries (2007) who discussed the quantitative uncertainty analysis of 24 LCA studies) and discussed [e.g.,Groen et al. (2014), Heijungs and Lenzen (2014) and Igos et al. (2018)] methods for uncertainty analysis in LCA. In these articles, uncertainty and variability were quantified together (as if they were interchangeable) and not separately in the same LCA study. To our knowledge, there has been made no attempt to review all methodologies that allow to decide if either uncertainty or variability is dominating in the results. For each methodology identified and included in the systematic review, we will study which visualization options exist and what the limitations are. We aim to select the most appropriate one(s), which allow to clearly conclude whether uncertainty or variability is dominating in the results, for future use in LCA. 


\section{Methods}

The search process and reporting of the systematic review is based on the PRISMA (Preferred Reporting Items for Systematic Reviews and Meta-Analyses) statement (Moher et al., 2009). This statement was very well-received as a tool for conducting systematic reviews, seeing as the PLoS Medicine publication has 20265 citations as of August 5, 2020.

For this systematic review, relevant published articles were identified by searching through the Web of Science Core Collection database, while "articles in press" were identified within Scopus. No restrictions were set for language or publication date. The reference lists of the articles included in the review were also checked for additional relevant studies. The last search was run on August 31, 2018. Four topics were defined that reflected the research question: uncertainty, variability, methodology and life cycle assessment. For each topic, a range of search terms was iteratively developed and tested. One search term of every topic had to be present in the title, abstract and/or keywords in order to be identified within the databases (fig. 1).

Eligibility criteria were specified in advance. These criteria were designed in a way to consecutively narrow down the pool of identified articles (thus criterion 1 has a much broader scope than criterion 4). Studies were found eligible to be included in the review if they met all of the following four criteria:

1. An LCA was conducted. The methodology needed to be usable within the LCA framework, and a fully worked out case study would provide valuable insights with regards to possibilities and limitations. Therefore, review papers or other types of assessments, such as risk assessment and assessments of fate, exposure and effects models, were excluded.

2. A clear distinction was made between uncertainty and variability in the inventory phase. Some kind of difference needed to be notable based on the given definitions, descriptions, input tables and/or graphs. It had to be clear which - and possibly how - input data reflected uncertainty and/or variability.

3. The effect of 'parameter uncertainty' and 'variability between sources and objects' were both considered, because - as stated before - those two types are the most feasible to be quantified in the inventory analysis (Huijbregts, 1998). Though, keeping in mind the different viewpoints discussed in the introduction, it was not required for those specific terms to be used in the selected articles. However, it was required that there was a possibility to justifiably assume that those two types were included, even when a different viewpoint was taken or when the authors did not thoroughly specify the distinction.

4. The applied methodology allowed the reader to conclude whether uncertainty or variability is dominating in the results. Thus, even when the authors did not specifically discuss that such a 
conclusion could be made, the reader would still be able to deduce it from the results shown in tables and/or graphs.

Identified studies were consecutively read carefully and their eligibility assessed based on the title (e.g., LCA was also used as an abbreviation for "last common ancestor), abstract and, when the abstract did not lead to a clear judgment, the full-text. The information found was structured as will be shown in the results section. One author was contacted because of unclearly reported information on the used methodology in their study, for which we got a response.

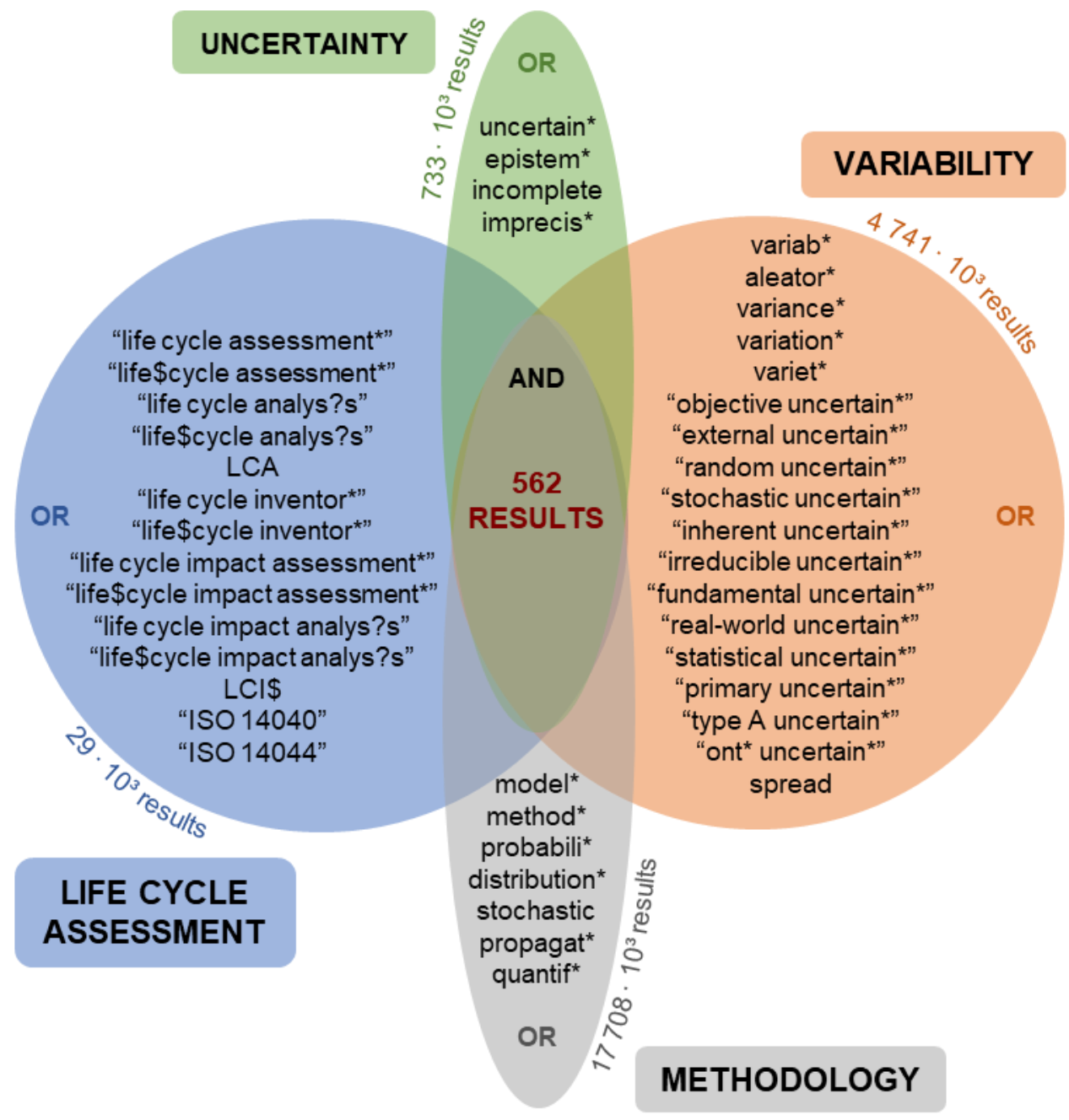

Fig. 1562 records were identified through database searching by combining search terms related to four main concepts (* represents any group of character(s), including no character; ? represents any single character; and $\$$ represents zero or one character)

\section{Results}

562 records were identified in Web of Science and Scopus based on the defined search strategy (fig. 1, 2). Not surprisingly, LCA was the limiting topic in the search strategy (fig. 1). Four duplicates were excluded. Subsequently, 558 records were screened on title and abstract, of which 397 records were 
excluded because the studies clearly did not meet the eligibility criteria. 161 records were assessed based on their full-text. For some articles, it was very clear from the full-text if they needed to be excluded [e.g., Sastre et al. (2015) and Venkatesh et al. (2011) stated that even though uncertainty and variability are inherently different, they considered them jointly]. In other articles, it was not so clear if the authors used the two terms more as synonyms or if a clear distinction was made.

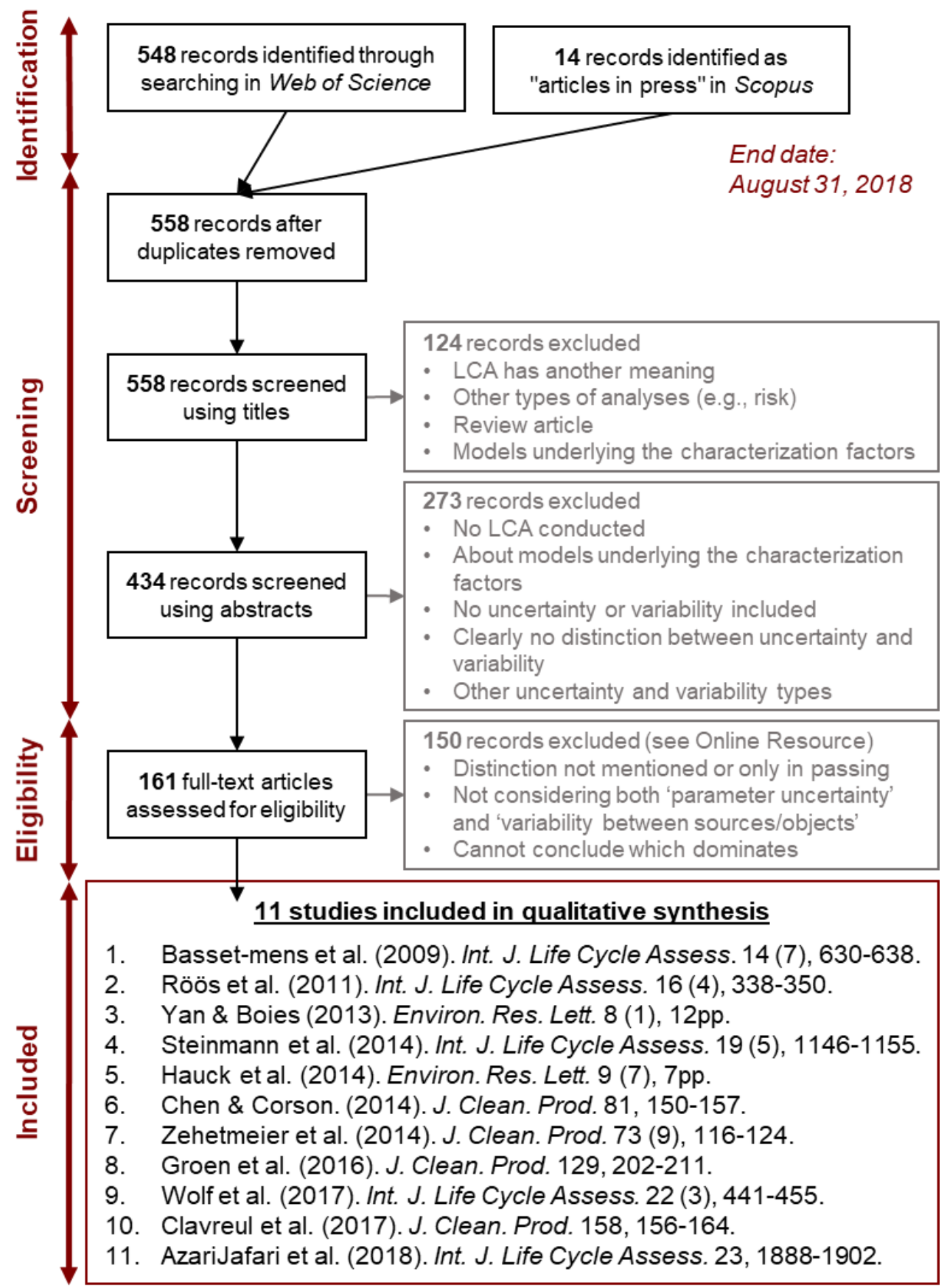

Fig. 2 Flow of information through the different phases of the systematic review

An Online Supplementary Material (ESM_1) is provided which shows the full-text eligibility check. It shows the main reason why an article was excluded from the systematic review and why in the end 
we could designate 11 out of 161 records as eligible. The three possible reasons, reflecting the eligibility criteria described in the methods section, were: (i) the article does not make a distinction between uncertainty and variability, or only in passing, (ii) the article does not take both 'parameter uncertainty' and 'variability between sources and objects' into consideration, and (iii) it cannot be concluded if either uncertainty or variability is dominating. It should be noted that ESM_1 only indicates the main reason why an article was not included, but that these three reasons are not mutually exclusive. This limited amount of final articles illustrates that researchers often treat uncertainty and variability alike, even when mentioning the importance of separating them. The reference lists of the eleven selected articles were checked for additional relevant studies, however none were found outside the defined search strategy.

From the eleven included articles, eight studies conducted an LCA of an agricultural product and three on energy generation (fig. 3). One of those articles (Yan and Boies, 2013) studied the environmental impact of a specific biofuel. The most recent article focused on pavements (AzariJafari et al., 2018). Hence, propagating variability seems especially relevant for LCAs of agricultural products, probably because of their inherently variable inventory data, e.g., different soil types, weather conditions, consumption patterns, etc. (Notarnicola et al., 2017).

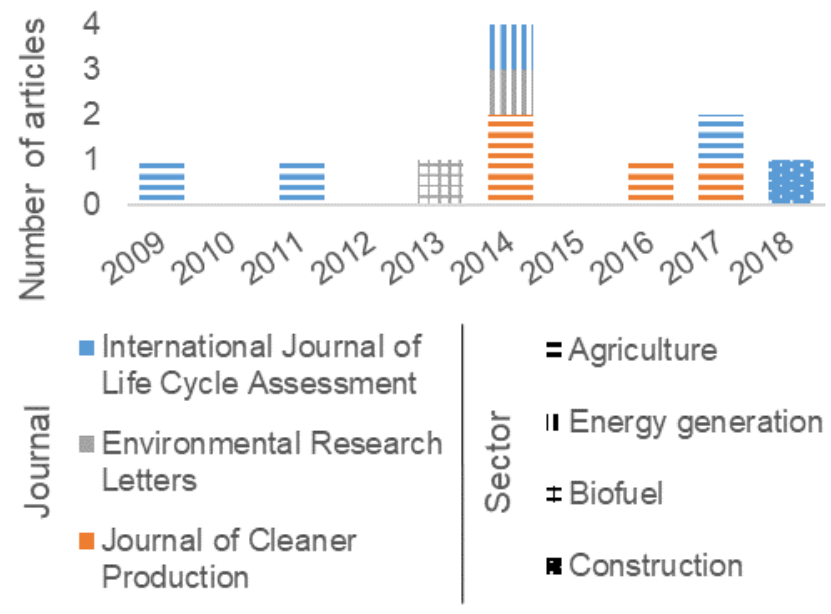

Fig. 3 Classification of the eleven included articles by year, journal (distinguished by color) and sector (distinguished by patterns)

Table 1 gives an overview of the eleven selected studies and their supplementary materials regarding their studied system, functional unit, system boundaries, geographical location, impact category, example sources of parameter uncertainty and variability between sources and objects, and on which information we could base the conclusion of whether uncertainty or variability is dominating. For readability, we will use the article ID's, as defined in table 1, throughout the remainder of the manuscript. The terminology used by the authors themselves is used in the table, illustrating the lack of harmonization. Nine (except ID 6 and 11) out of the eleven articles focused exclusively on the 
impact category climate change, using terms such as "global warming potential", "carbon footprint", "greenhouse gas intensity" and "(life cycle) greenhouse gas emissions".

Fig. 4 shows in which of the included articles a conclusion can be drawn regarding specific type(s) of uncertainty and variability. The type is either (i) propagated on its' own, (ii) propagated alongside another type because it was not feasible (or relevant) to separate the types, or (iii) the type was not considered. A type was only included if the type [as defined by Huijbregts (1998)] was explicitly mentioned by the article or if we could deduce it based on the given definitions. For example, the study done by Zehetmeier et al. (2014) (ID 7) presented a clear table showing how each parameter was classified to a certain type or several types of uncertainty and variability.

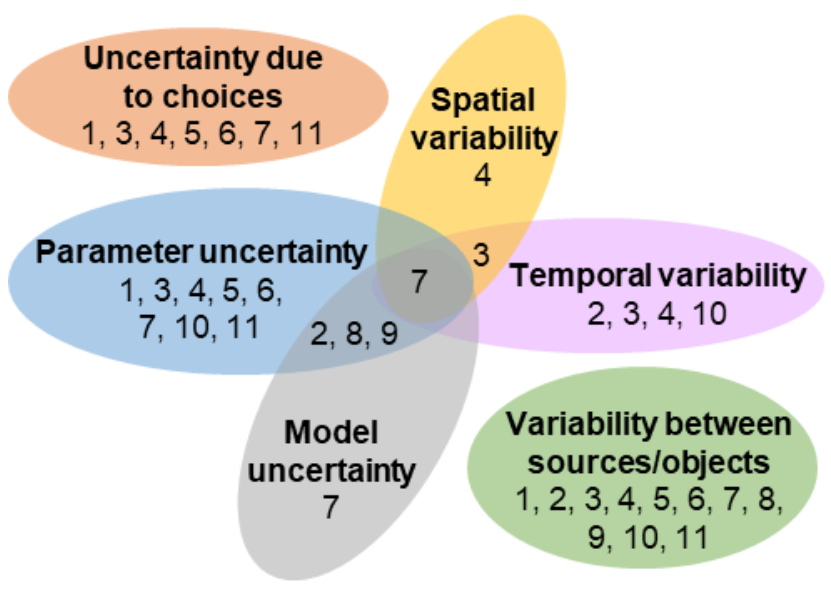

Fig. 4 Venn-diagram showing in which articles (using article ID's as defined in table 1) a conclusion can be drawn regarding specific type(s) of uncertainty and variability (note: an article ID such as 7, can appear more than once in a specific type depending on how the different input parameters are classified)

If the authors used a different viewpoint for the uncertainty classification, the sources of uncertainty and variability were interpreted from the perspective of Huijbregts' classification (1998). If no clear terminology or definitions were given, then it was deduced based on context and other information given in the study. Sometimes, some assumptions had to be made regarding the sources of uncertainty and variability to compare and assess the effectiveness of the methodology. For example, Clavreul et al. (2017) (ID 10) distinguished between the "primary data", described as the variability in farmer's inputs, and the "secondary data", which they described using both "model uncertainties" and "uncertainty in model parameters". However, they did not give an explicit definition about these terms. Even though the primary data can also include parameter uncertainty, in this systematic review they were classified as variability between sources and objects based on their given description. The secondary data were classified as having parameter uncertainty.

Yan and Boies (2013) (ID 3) refer to the uncertainty and variability classification shown in Lloyd and Ries (2007), where uncertainty and variability sources can be classified according to three possible LCA modeling components i.e., parameter (input date), scenario (normative choice) or model 
(mathematical relationships). However, they used an unreferenced subclassification for parameter uncertainty (consisting of both uncertainty and variability for this classification), i.e.: "statistical uncertainty", "temporal/spatial variability", "data limitation" and "scientific uncertainty". Based on the used classification and the given definitions, we classified "statistical uncertainty" as variability between sources and objects; and "data limitation" and "scientific uncertainty" as parameter uncertainty. Groen et al. (2016) (ID 8) and Wolf et al (2017) (ID 9) based their classification on Walker et al. (2003), thus distinguishing between "epistemic uncertainty" and "variability uncertainty".

Furthermore, Chen and Corson (2014) (ID 6) added uncertainty in emission factors to a study done by van der Werf et al. (2009) which already included variability in farm characteristics. Their aim was to assess how the inclusion of a different type of uncertainty to an already existing LCA study changes the interpretation. However, they stated that, because of the references they used, epistemic uncertainty and variability could not be clearly separated in the uncertainty ranges of the emissions factors. Nevertheless, seeing as they specifically wanted to separate the two sources of uncertainty and because, in this systematic review, we are especially interested to see which methodologies are used to propagate that separation, it was chosen to classify the emission factors as belonging to parameter uncertainty.

ISO 14040/44 (2006a, 2006b) did not provide specific definitions and classifications for uncertainty and variability. It is clear that since then, no consensus has been reached regarding the terminology and definitions for the different types of uncertainty and variability.

Typical parameter uncertainty sources were electricity use and emissions, while variability between sources and objects was often found in yield data and lifetimes (table 1). Next to this, uncertainty due to choices was the most frequently assessed (fig 4). The most prominent source of that uncertainty type was related to the choice of the impact assessment method (ID 1, 4, 5 and 11). Especially the choice of the Global Warming Potential (GWP) time horizon, which varied between 20, 100 and 500 years (ID 1, 4 and 5), was often taken into account. While the LCA practitioner can deal with parameter uncertainty and variability between sources and objects through e.g., propagation, dealing with uncertainty due to choices is more study-specific and often related to following guidelines and standards. 
Table 1 Overview of the eleven selected articles (using the terminology of each individual paper), listing (i) the identification number (ID) used in the review, (ii) the source, (iii) the researched system, (iv) the functional unit, (v) the chosen system boundary, (vi) the geographical location of the system, (vii) the considered impact categories, (viii \& ix) where the sources of parameter uncertainty and variability between sources and objects can be found in the selected articles and a few examples of those, and (x) where we could find the information to base the conclusion of whether uncertainty or variability is more dominating in the results, followed after ":" with the actual conclusion made, either formulated or explicitly discussed in the text or deduced by combining information in the paper. Further information on why and which assumptions we had to make regarding the classification of uncertainty and variability is given in the results section. $(\mathrm{GWP}=$ Global Warming Potential; $\mathrm{GHG}=$ greenhouse gas; $\mathrm{FU}=$ functional unit $)$

\begin{tabular}{|c|c|c|c|c|c|c|c|c|c|}
\hline ID & Source & System & Functional unit & System boundary & Location & $\begin{array}{l}\text { Impact } \\
\text { category }\end{array}$ & $\begin{array}{l}\text { Sources of } \\
\text { parameter } \\
\text { uncertainty }\end{array}$ & $\begin{array}{l}\text { Sources of } \\
\text { variability between } \\
\text { sources/objects }\end{array}$ & $\begin{array}{l}\text { Uncertainty or } \\
\text { variability } \\
\text { dominating? }\end{array}$ \\
\hline 1 & $\begin{array}{l}\text { (Basset- } \\
\text { mens et al., } \\
2009)\end{array}$ & $\begin{array}{l}\text { Milk } \\
\text { production }\end{array}$ & $\begin{array}{l}1 \mathrm{~kg} \text { of New- } \\
\text { Zealand milk }\end{array}$ & Cradle-to-farm-gate & $\begin{array}{l}\text { New- } \\
\text { Zealand }\end{array}$ & GWP & $\begin{array}{l}\text { Table 1: milk yield, } \\
\text { feed supplements, etc. }\end{array}$ & $\begin{array}{l}\text { Table 1: milk } \\
\text { yield, feed } \\
\text { supplements, etc. }\end{array}$ & $\begin{array}{l}\text { Fig. 1, table 3, } \\
\text { section 3.1: } \\
\text { variability }\end{array}$ \\
\hline 2 & $\begin{array}{l}\text { (Röös et al., } \\
2011)\end{array}$ & $\begin{array}{l}\text { Refined } \\
\text { wheat } \\
\text { products }\end{array}$ & $\begin{array}{l}1 \mathrm{~kg} \text { of wheat } \\
\text { before the } \\
\text { milling process }^{\mathrm{a}}\end{array}$ & Cradle-to-mill & Sweden & $\begin{array}{l}\text { Carbon } \\
\text { footprint }\end{array}$ & $\begin{array}{l}\text { Table 3: wheat yield, } \\
\text { amount of } \mathrm{N} \text { fertilizer, } \\
\text { distance farm to mill, } \\
\text { etc. }\end{array}$ & $\begin{array}{l}\text { Table 3: wheat } \\
\text { yield, amount of } \\
\mathrm{N} \text { fertilizer, } \\
\text { distance farm to } \\
\text { mill, etc. }\end{array}$ & $\begin{array}{l}\text { Fig. } 2 \text {, table } 5 \text {, } \\
\text { section } 3.2 \text { : } \\
\text { uncertainty (for the } \\
\text { scenario for which } \\
\text { soil } \mathrm{N}_{2} \mathrm{O} \text { emission } \\
\text { uncertainty was } \\
\text { included), etc. }\end{array}$ \\
\hline 3 & $\begin{array}{l}\text { (Yan and } \\
\text { Boies, } \\
\text { 2013) }\end{array}$ & $\begin{array}{l}\text { Wheat } \\
\text { ethanol }\end{array}$ & $\begin{array}{l}1 \mathrm{MJ} \text { of final fuel } \\
\text { energy produced }\end{array}$ & $\begin{array}{l}\text { Considered life cycle stages: } \\
\text { agriculture, wheat transport } \\
\text { and handling, biorefinery, } \\
\text { ethanol distribution and } \\
\text { potential land use change }\end{array}$ & $\begin{array}{l}\text { United } \\
\text { Kingdom }\end{array}$ & GHG intensity & $\begin{array}{l}\text { Table S3 Run 4-6: } \\
\text { embedded GHG in } \\
\text { pesticide, transport } \\
\text { distance, etc. }\end{array}$ & $\begin{array}{l}\text { Table S3 Run 1: grain } \\
\text { yield, N application } \\
\text { rate, etc. }\end{array}$ & $\begin{array}{l}\text { Fig. 2, section 3: } \\
\text { uncertainty }\end{array}$ \\
\hline 4 & $\begin{array}{l}\text { (Steinmann } \\
\text { et al., 2014) }\end{array}$ & $\begin{array}{l}\text { Coal- } \\
\text { fueled } \\
\text { power } \\
\text { generation }\end{array}$ & $\begin{array}{l}1 \mathrm{kWh} \text { of } \\
\text { electricity } \\
\text { generated at a } \\
\text { plant or plants in }\end{array}$ & Mine to wire & USA & $\begin{array}{l}\text { Life cycle } \\
\text { GHG } \\
\text { emissions }\end{array}$ & $\begin{array}{l}\text { Table S1: electricity } \\
\text { use for surface } \\
\text { mining, diesel use } \\
\text { truck, etc. }\end{array}$ & $\begin{array}{l}\text { Introduction p. 1147: } \\
\text { mine type, mode of } \\
\text { transport, etc. }\end{array}$ & $\begin{array}{l}\text { Fig. } 2 \text {, fig. } 4 \text {, section } \\
\text { 3.1: variability }\end{array}$ \\
\hline
\end{tabular}




\begin{tabular}{|c|c|c|c|c|c|c|c|c|c|}
\hline & & & $\begin{array}{l}\text { a particular } \\
\text { calendar year }\end{array}$ & & & & & & \\
\hline 5 & $\begin{array}{l}\text { (Hauck et } \\
\text { al., 2014) }\end{array}$ & $\begin{array}{l}\text { Gas power } \\
\text { generation }\end{array}$ & $\begin{array}{l}1 \mathrm{kWh} \text { of } \\
\text { electricity } \\
\text { generated at the } \\
\text { power plant }\end{array}$ & Well to wire & USA & $\begin{array}{l}\text { Life cycle } \\
\text { GHG } \\
\text { emissions }\end{array}$ & $\begin{array}{l}\text { S3: well life time, } \\
\text { gas turbine heat } \\
\text { rate, etc. }\end{array}$ & $\begin{array}{l}\text { Figure } 1 \text { caption: } \\
\text { production practice, } \\
\text { processing } \\
\text { technology, etc. }\end{array}$ & $\begin{array}{l}\text { Fig. 2, fig. 3, fig. } 4 \text {, } \\
\text { section } 3.1 \text { : } \\
\text { variability }\end{array}$ \\
\hline 6 & $\begin{array}{l}\text { (Chen and } \\
\text { Corson, } \\
\text { 2014) }\end{array}$ & $\begin{array}{l}\text { Dairy } \\
\text { farms }\end{array}$ & $\begin{array}{l}1 \text { ha of on-farm } \\
\text { usable } \\
\text { agricultural area } \\
\& 1000 \mathrm{~kg} \text { of fat- } \\
\text { and-protein- } \\
\text { corrected milk } \\
\text { sold }\end{array}$ & $\begin{array}{l}\text { Cradle-to-farm-gate; with } \\
\text { exclusion of all inputs, } \\
\text { output and usable } \\
\text { agricultural area of cash } \\
\text { crops to retain only the milk- } \\
\text { production subsystem for the } \\
\text { "milk" functional unit }\end{array}$ & France & $\begin{array}{l}\text { Climate } \\
\text { change, } \\
\text { acidification, } \\
\text { eutrophication }\end{array}$ & $\begin{array}{l}\text { Table 1: } \mathrm{NH}_{3} \text { from } \\
\text { manure spreading, } \\
\text { mineral fertilizer } \\
\text { application, etc. }\end{array}$ & $\begin{array}{l}\text { Section 2.3: farm } \\
\text { characteristics }\end{array}$ & $\begin{array}{l}\text { Fig. 2, section } 3.1 \text {, } \\
\text { section } 4.1 \text { : } \\
\text { variability (for } \\
\text { eutrophication, for } \\
\text { FU per ha of usable } \\
\text { agricultural land), } \\
\text { etc. }\end{array}$ \\
\hline 7 & $\begin{array}{l}\text { (Zehetmeier } \\
\text { et al., 2014) }\end{array}$ & $\begin{array}{l}\text { Dairy cow } \\
\text { production } \\
\text { systems }\end{array}$ & $1 \mathrm{~kg}$ of milk & $\begin{array}{l}\text { Dairy farm gate \& system } \\
\text { expansion: dairy farm gate } \\
\text { and fattening systems farm } \\
\text { gate }\end{array}$ & Germany & $\begin{array}{l}\text { GHG } \\
\text { emissions }\end{array}$ & $\begin{array}{l}\text { Table 1: emission } \\
\text { factor nitrogen input } \\
\text { into soil and } \\
\text { emission factor beef } \\
\text { from suckler cow } \\
\text { production }\end{array}$ & $\begin{array}{l}\text { Table 1: calving } \\
\text { interval/replacement } \\
\text { rate }\end{array}$ & $\begin{array}{l}\text { Fig. } 2 \text {, table } 4 \text {, } \\
\text { section } 3.1 \text {, section } \\
\text { 3.2: uncertainty }\end{array}$ \\
\hline 8 & $\begin{array}{l}\text { (Groen et } \\
\text { al., 2016b) }\end{array}$ & $\begin{array}{l}\text { Pork } \\
\text { production }\end{array}$ & $\begin{array}{l}1 \mathrm{~kg} \text { body weight } \\
\text { of a growing pig }\end{array}$ & $\begin{array}{l}\text { Processes considered in the } \\
\text { pig chain: production of crop } \\
\text { inputs, feed processing, } \\
\text { piglet production, manure } \\
\text { management, pig housing, } \\
\text { and enteric fermentation } \\
\text { from pigs }\end{array}$ & $\begin{array}{l}\text { The } \\
\text { Netherlands }\end{array}$ & $\begin{array}{l}\text { GHG } \\
\text { emissions }\end{array}$ & $\begin{array}{l}\text { Section 2.5.4: } \mathrm{N}_{2} \mathrm{O} \\
\text { emissions of feed- } \\
\text { crop production, } \\
\mathrm{CH}_{4} \text { emissions of } \\
\text { manure } \\
\text { management, etc. }\end{array}$ & $\begin{array}{l}\text { Section 2.5.4: crop } \\
\text { yield, feed intake, etc. }\end{array}$ & Fig. 7: uncertainty \\
\hline
\end{tabular}




\begin{tabular}{|c|c|c|c|c|c|c|c|c|c|}
\hline 9 & $\begin{array}{l}\text { (Wolf et al., } \\
\text { 2017) }\end{array}$ & $\begin{array}{l}\text { Milk } \\
\text { production }\end{array}$ & $\begin{array}{l}1 \mathrm{~kg} \text { of energy } \\
\text { corrected milk } \\
(\mathrm{ECM})\end{array}$ & Cradle-to-farm gate & Germany & $\begin{array}{l}\text { GHG } \\
\text { emissions }\end{array}$ & $\begin{array}{l}\text { Fig. } 5 \text { : direct } \mathrm{N}_{2} \mathrm{O} \\
\text { crop cultivation, } \\
\mathrm{CH}_{4} \text { manure, etc. }\end{array}$ & $\begin{array}{l}\text { Fig. 5: milk yield, } \\
\text { replacement rate, etc. }\end{array}$ & $\begin{array}{l}\text { Fig. 5, fig. 6: } \\
\text { uncertainty }\end{array}$ \\
\hline 10 & $\begin{array}{l}\text { (Clavreul et } \\
\text { al., 2017) }\end{array}$ & $\begin{array}{l}\text { Open-field } \\
\text { tomato } \\
\text { production }\end{array}$ & $\begin{array}{l}1 \text { tonne fresh } \\
\text { tomato }\end{array}$ & Farm gate & $\begin{array}{l}\text { Extremadur } \\
\text { a region } \\
\text { across Spain } \\
\text { and Portugal }\end{array}$ & $\begin{array}{l}\text { Carbon } \\
\text { footprint }\end{array}$ & $\begin{array}{l}\text { Table 2: } \mathrm{N}_{2} \mathrm{O} \text { direct } \\
\text { emissions, } \mathrm{GHG} \\
\text { emissions from } \\
\text { fertilizer } \\
\text { production, etc. }\end{array}$ & $\begin{array}{l}\text { Table 1: nitrogen } \\
\text { input, diesel use, etc. }\end{array}$ & $\begin{array}{l}\text { Fig. } 5 \text {, fig. } 6 \text {, section } \\
\text { 3.2: variability }\end{array}$ \\
\hline 11 & $\begin{array}{l}\text { (AzariJafari } \\
\text { et al., 2018) }\end{array}$ & Pavements & $\begin{array}{l}\text { Providing a path } \\
\text { for traffic service } \\
\text { for } 20000 \\
\text { Annual Average } \\
\text { Daily Traffic } \\
\text { including } 5 \% \text { of } \\
\text { the truck, over } 1 \\
\text { km length of a } \\
\text { two lanes road in } \\
\text { Quebec urban } \\
\text { area and for a } \\
50 \text {-year lifespan }\end{array}$ & Cradle-to-grave & $\begin{array}{l}\text { Province of } \\
\text { Quebec } \\
\text { (Canada) }\end{array}$ & $\begin{array}{l}\text { Midpoint \& } \\
\text { endpoint } \\
\text { impact } \\
\text { categories of } \\
\text { IMPACT } \\
2002+\end{array}$ & $\begin{array}{l}\text { Table S7: } \\
\text { equipment, } \\
\text { electricity, etc. }\end{array}$ & $\begin{array}{l}\text { Section 2.2.4.2: } \\
\text { pavement lifetime, } \\
\text { variation in materials, } \\
\text { etc. }\end{array}$ & $\begin{array}{l}\text { Fig. } 4 \text {, fig. } 5 \text {, section } \\
\text { 3.2: uncertainty (for } \\
\text { ecosystem quality), } \\
\text { etc. }\end{array}$ \\
\hline
\end{tabular}

a The study also included a functional unit of "1 kg of KGI (Kungsörnens Gammeldags Idealmakaroner, a common Swedish pasta variety) in paper packaging available for sale in a supermarket in Stockholm" with a cradle-to-retail functional unit, but was not used in the reviewed methodology for propagating uncertainty and variability separately and therefore not included in the overview 


\section{Discussion}

It is clear that the origin and implications of epistemic uncertainty and variability differ. By assessing the nature of uncertainty, we can know if the quality of the output can be improved by additional research, which is only the case for epistemic uncertainty (Walker et al., 2003). However, variability can also further guide system optimization, product development or policy (Steinmann et al., 2014). A clear distinction between epistemic uncertainty and variability may help decision makers to judge differences in product comparisons, options for product improvements or the assignment of ecolabels (Huijbregts, 1998).

For example, regarding options for product improvements, we noticed in Goossens et al. (2017) that it is possible to produce 1 ton apples with low impacts across all impact categories, thereby illustrating the importance of assessing the variability in managerial influence. If variability would have been included within the broad concept of uncertainty, then this feature would not have been noticeable during the interpretation phase. Outliers would have been considered as inherent to the uncertainty and actors would not have known that it is caused by a real variation. Moreover, regarding product comparisons, separating uncertainty and variability is also especially relevant when comparing biobased products, derived from natural systems, with abiotic ones, for which conditions are controlled and often standardized. Bio-based products are subject to environmental conditions, which can cause a lot of variability in the data (Milà i Canals et al., 2011). When comparing, for example, LCA's of biofuels with fossil fuels, it is likely that variability will dominate the biofuel's LCA results, while uncertainty will dominate the ones of fossil fuel. In that case, the distinction will only be noticeable after clear separation of uncertainty and variability, and suitable decisions can only be drawn after proper communication to decision makers. These examples illustrate the general need for quantifying uncertainty and variability in LCA.

\subsection{Classification of parameters}

As stated previously, the goal of this systematic review is to study which methodologies have been used in LCA to separately account for uncertainty and variability in the results. For this we will first discuss the classification of the parameters used by the eleven included articles because it impacts the review. Whereas people may expect that definitions are clear, it became obvious during our study that the classification of parameters as belonging to one or more of the different types of uncertainty and variability in the data inventory phase, is study-specific (see example sources of parameter uncertainty and variability between sources and objects in table 1). It depends on Goal \& Scope Definition (Huijbregts, 1998) and data quality.

In the goal definition, researchers define the reasons for carrying out their study (ISO, 2006a). As can be seen in table 1 and figure 4 , this has prominent consequences on which types of uncertainty and 
variability will be taken into consideration. For example Basset-mens et al. (2009) (ID 1) set out to calculate the Global Warming Potential (GWP) of New-Zealand milk, because decision makers seek to understand the significance of changing milk production due to refining New Zealand's agricultural management. By using national statistics, they explicitly propagated variability between sources and objects (i.e. farms), which inherently included spatial variability. However, rather than focusing on geographical location (e.g., compare the GWP caused by the milk production in the North Island with the South Island), only the inter-farm variability was relevant for their goal.

The scope definition comes into play by defining the back- and foreground system and the functional unit (ISO, 2006a). The foreground system is commonly defined as comprising those processes of a system that are specific to it, and are largely modelled using primary data i.e., data collected first-hand by the LCA practitioner. In contrast, the background system is commonly defined as those processes of a system that are not specific to it, and are typically modelled using life cycle inventory databases (Hauschild et al., 2018). This distinction influences the choice of classifying data as either deterministic, uncertain, variable or both uncertain and variable. Data collected in the foreground system for one individual life cycle tend to be more easily accepted as being deterministic by LCA practitioners. Though, data in the foreground system can also be uncertain and variable, that information is often not considered or unavailable during collection. Regarding uncertainty, foreground parameters are expected to have lower uncertainty than background parameters, given that the LCA practitioner should have made sure that the collected data is reliable. Furthermore, an extensive foreground system, containing different individual life cycles, can be in itself an indication of variability. For example Steinmann et al. (2014) (ID 4) and Hauck et al. (2014) (ID 5) used the deterministic data of a relatively large number of plant-specific life cycles to calculate a variability ratio. Thus, their input parameters were either deterministic or had an uncertain distribution assigned to it, but not a variable one. In contrast, the background system should - in theory - always include uncertainty and variability, seeing as it is not specific to the studied system. However, the data quality of the database determines if that kind of information is available.

Furthermore, certain parameters can be classified as either parameter or model uncertainty. For example, emissions can either be measured relative to a specific functional unit and incorporated as parameters or they can be modeled mathematically in relation to input parameters (Lloyd and Ries, 2007). In the selected articles, $\mathrm{Yan}$ and Boies (2013) (ID 3 ) clearly define soil $\mathrm{N}_{2} \mathrm{O}$ emission from fertilizer use as "scientific uncertainty" (i.e., parameters that are currently highly uncertain with the best available science) which they defined as being part of parameter uncertainty. Clavreul et al. (2017) (ID 10) considered direct $\mathrm{N}_{2} \mathrm{O}$ field emissions as having "model uncertainties". However, as stated in the results, due to unclear terminology and non-reported definitions, we classified it as parameter uncertainty. Zehetmeier et al. (2014) (ID 7) classified the emission factor of nitrogen input into soil as having both model uncertainty and parameter uncertainty. 
It is clear that distinction between the different types of uncertainty is not straightforward, often because an input parameter can be considered as belonging to different types, or insufficient data is available. Several authors (ID 2, 4 and 6) stated that it was not feasible for them to clearly separate uncertainty and variability in their parameters, and the parameter was subsequently considered as uncertain.

It may be interesting to further subdivide variability between sources and objects in inter-individual [as defined by the U.S. EPA (Wood et al., 1997)] and technological variability [as used by Steinmann et al. (2014) (ID 4) and Hauck et al. (2014) (ID 5)], because technological variability can provide information on how processes can be improved, as opposed to inter-individual variability.

\subsection{Propagation, visualizations and limitations}

The chosen methodology has a big influence on how the distinction between uncertainty and variability can be made, how it can be propagated and analyzed, how it can be visualized and what kind of conclusions can be drawn regarding the dominance of either uncertainty or variability. All the included methodologies in this systematic review generally follow the different steps for treatment of uncertainty (which includes variability) of LCA models, as described by Igos et al. (2018): (i) characterization, i.e., the qualitative and quantitative description of uncertainties from the model and inputs; (ii) uncertainty analysis, i.e., the propagation of uncertainty to the outputs; (iii) sensitivity analysis, i.e., the analysis of the influence of input uncertainty on output uncertainty; and (iv) communication, i.e., the ability to inform the audience about uncertainty. Each methodology that was used in the articles to propagate the different types of uncertainty and variability - in particular focusing on parameter uncertainty and variability between sources and objects - is qualitatively analyzed in the following sections. Uncertainty analysis and sensitivity analysis are distinct but related disciplines and often conflated in literature (Saltelli et al., 2019). The different methodologies were therefore categorized as uncertainty and variability propagation, local sensitivity analysis, screening method and global sensitivity analysis; to clearly distinguish between the different types of analyses.

Since LCA results are becoming more and more disseminated [e.g., for the Product Environmental Footprint (European Commission, 2018), by companies (BASF, 2018; Unilever, 2018), etc.], clear communication of the uncertainty component (including variability) is required to avoid biased interpretations from non-experts (Igos et al., 2018). Therefore, a proper LCA study should communicate all different components related to the uncertainty and variability quantification, from defining the concepts and identifying the sources, to the propagation of these sources (Hauschild et al., 2018; Igos et al., 2018). The chosen communication form should be understandable and clear for the target audience. It should enhance the interpretation and lead to robust conclusions, keeping in 
mind that the same information can be interpreted differently depending on the audience's context and their familiarity with the concepts (Hauschild et al., 2018).

Hauschild et al (2018) list four different, complementary ways to present uncertainty information: (i) qualitatively (e.g., reporting sources of uncertainty/variability and their potential influence on results), (ii) descriptively (e.g., summary statistics), (iii) graphically and (4) numerically (e.g., ranges, probability distributions of results or statistical results). In the following review, all these ways are considered, but the focus lies especially on graphical visualization, because it allows to show a lot of information in a concise and structured way. However, it also bears the risk of being suggestive and easily misinterpreted (Hauschild et al., 2018), or it might be too complex or conversely, too simple, depending on the degree of detail and nuance included. Figure 5 shows how the results were visualized in the selected studies for the specific methodologies used for all the considered types of uncertainty and variability. The data used in the visualization options, part of figure 5, has no link with the data in the eleven included articles, only with their methodologies. These illustrative data were chosen to always have variability be the most dominating.

\subsubsection{Uncertainty and variability propagation}

Processing uncertainty in LCA is usually done by using either a sampling method or an analytical method (Heijungs and Lenzen, 2014; Igos et al., 2018), however other methods such as scenario analysis, interval calculations and fuzzy set theory were also occasionally used (Igos et al., 2018; Lloyd and Ries, 2007).

The aim with sampling methods is to simulate several result possibilities represented by a probability distribution, by sampling inputs from probability distributions (Hauschild et al., 2018; Igos et al., 2018). In contrast, in the analytical approach the first-order approximation of the Taylor series expansion is usually used to determine the variance of the output based on the variances of the uncertain inputs. Its main advantages are calculation speed and smaller data requirements. The drawback are that less uncertainty information can be obtained from the result and that it is predominately applicable for simple models with small uncertainties (Groen et al., 2014; Heijungs and Lenzen, 2014).

Scenario analysis for uncertainty analysis leads to a range of possible LCA results calculated from different model formulations (Igos et al., 2018). Fuzzy sets - which is an extension of interval calculations (Igos et al., 2018) - simulate the way an expert reasons by degrees of plausibility or possibility, rather than frequency, of an uncertain parameter value. This is mostly displayed by triangular or trapezoidal distributions, based on a lower and upper bound (support) and a most plausible value or interval (core), respectively. Narrower intervals of this distribution at any given degree of possibility $\alpha$ (from 0 to 1 ), are called $\alpha$-cuts, which can be manipulated using interval arithmetic. The computational effort is limited, seeing as only a few $\alpha$-cuts are needed (e.g., 20) to 
give insight into the output uncertainty. The result of this method is a possibility function - combining the inventory results at all $\alpha$-cuts - with a core value (of height equal 1 ) and a lower and upper bound, for which the resolution is determined by the number of propagated $\alpha$-cuts (Groen et al., 2014; Igos et al., 2018; Tan, 2008).

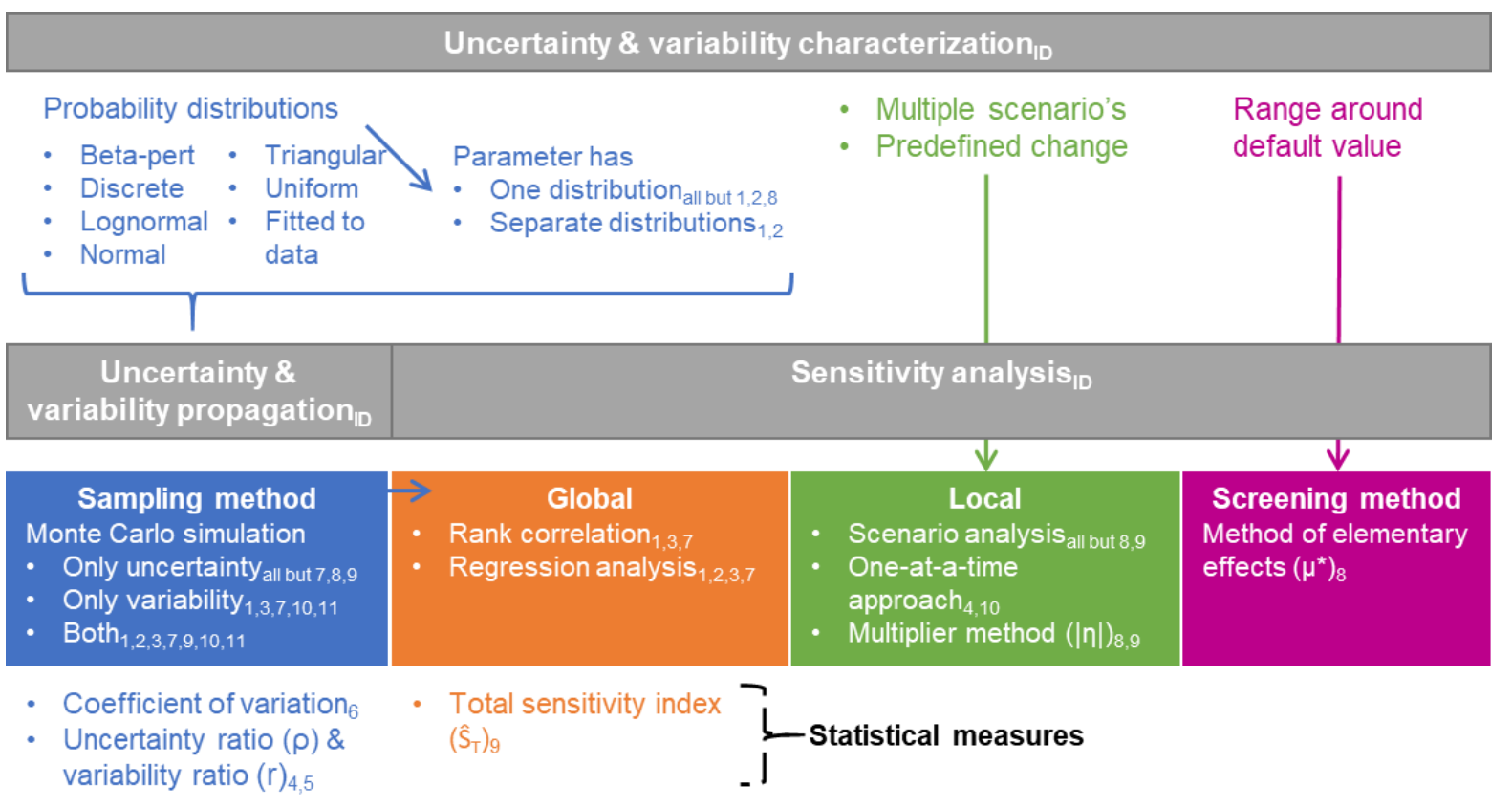

\section{Visualization options (Which one is dominating: uncertainty or variability?)}

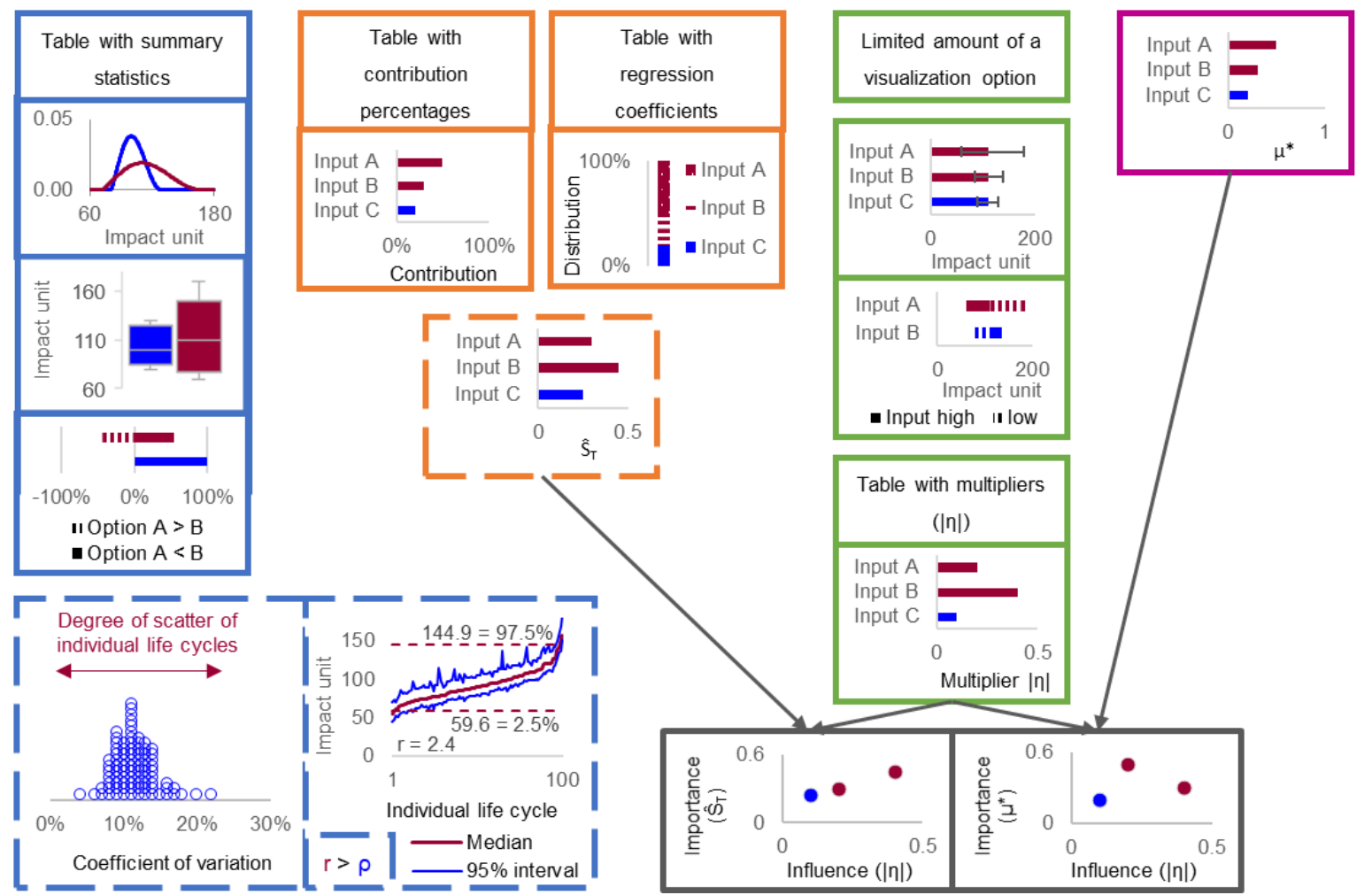

Fig. 5 Overview of the steps taken by the different articles (indicated by ID's as defined in table 1) to visualize uncertainty and variability in the results (the used data in the visualization options is fictional and chosen to have variability dominating; striped frames show visualizations where statistical measures are applied) 
In the selected articles, only sampling methods i.e., Monte Carlo simulations, were used to propagate uncertainty and variability separately. Therefore, the other possible methods for uncertainty propagation in LCA are not further discussed; more extensive overviews can be found in e.g., Groen et al., (2014), Hauschild et al. (2018), Heijungs and Huijbregts (2004), Igos et al. (2018) and Lloyd and Ries (2007).

\section{Monte Carlo simulations}

The most commonly used sampling method in LCA is Monte Carlo simulation (Groen et al., 2014; Hauschild et al., 2018; Igos et al., 2018), available in all major LCA software (Hauschild et al., 2018). The method was used in ten out of the eleven included studies (all except ID 8). The basic principle of this sampling method is conducting iterations of model calculations using values sampled from defined probability distributions for each input parameter. Therefore, the model output can be represented by a probability distribution as well (Hauschild et al., 2018; Igos et al., 2018) as illustrated in the first graph in light blue on the left of fig. 5. Any Monte Carlo simulation has the same basic, iterative process, but the way values are randomly sampled from the probability distribution can vary (Hauschild et al., 2018). Sampling can be done using e.g., Monte Carlo sampling, Latin Hypercube sampling (Groen et al., 2014; Hauschild et al., 2018; Heijungs and Lenzen, 2014) and Quasi-Monte Carlo sampling (Groen et al., 2014; Igos et al., 2018). One of the selected articles (ID 1) specifically stated that they used Latin Hypercube, because the stratified sampling without replacement leads to a quicker stabilization of the results (Hauck et al., 2014).

One of the included articles (ID 1) visualized the results from the simulations with probability distributions and three (ID 3, 5 and 10) used box plots (second illustrative graph in light blue on the left of fig. 5). Monte Carlo simulations are in the selected studies most often used to firmly separate the different types of uncertainty and variability, with scenarios-like outcomes (ID 1-3, 10 and 11). One or more types are considered as deterministic, while the other considered types are sampled from during the iterations, and the combined effect of all types is often propagated as well (ID 10 and 11).

Propagating parameter uncertainty in the selected articles by means of Monte Carlo simulations was done by sampling exclusively from distributions reflecting uncertainty (ID 1-6, 10 and 11). A distinction can be made between studies that propagate specific parameters as only being uncertain (ID $3-6$ and 10), and studies that assign uncertainty distributions and variability distributions to each parameter (ID 1 and 2). The assigned distributions are: uniform, triangular or beta-pert, depending on available values (ID 3 - 5 and 10); normal or lognormal, using the standard error of the mean (ID 1); or lognormal, using arithmetic metrics (ID 5), using geometric metrics (ID 2, 4 and 5), or using the uncertainty factors of the pedigree matrix (ID 11).

Propagating variability between objects and choices is done similarly as parameter uncertainty. Monte Carlo simulations were conducted, sampling exclusively from distributions reflecting variability (ID 
1, 3, 7, 10 and 11). The assigned distributions are: discrete (ID 10), uniform (ID 11), or normal or lognormal, using the standard deviation (ID 1, 3, 7 and 10) as opposed to using the standard error of the mean for propagating parameter uncertainty (ID 1).

Exclusively sampling from uncertainty distributions versus variability distributions leads to scenariolike outcomes. In this case, a choice needs to be made about which kind of statistic, based on the resulting probability distribution, is a proper indication to determine whether uncertainty or variability is most dominating. The resulting probability distribution of the Monte Carlo simulations are expressed in the selected articles using: median values (ID 3), standard deviation (ID 1 and 10), ranges [e.g. $5^{\text {th }}-95^{\text {th }}$ percentiles (ID 1 and 3), $2.5^{\text {th }}-97.5^{\text {th }}$ percentiles (ID 2), $0^{\text {th }}-100^{\text {th }}$ percentiles (ID 1)] and skewness (ID 1).

AzariJafari et al. (2018) (ID 11) also sampled exclusively from one type of uncertainty or variability, but had a slightly different approach. Instead of propagating uncertainty and variability for one product system, they took the relative uncertainty and the relative variability of two products (option A and option B; see third illustrative graph in light blue on the left of fig. 5) into consideration through a pair-wise analysis (A-B). For each impact category, the analysis shows if relative uncertainty and/or relative variability is a dominating factor in the selection of the preferred product (i.e. in how many iterations has option A less impact than option B when considering only relative uncertainty or only relative variability). For example, in $100 \%$ of the iterations, option A had less impact on climate change than option $B$, when only considering uncertainty. In contrast, when only considering variability, option A was the preferred option regarding climate change in only a little more than $50 \%$ of the iterations.

Some studies propagated parameter uncertainty and variability between sources and objects alongside each other during Monte Carlo simulations. There are three distinct methods used: (i) sampling from both uncertainty distributions and variability distributions, after having conducted simulations for each separately (ID 10 and 11), which - of course - causes a larger spread in the results; (ii) conducting two Monte Carlo simulations, sampling exclusively from uncertainty distributions and sampling from both distribution types (ID 2); and (iii) conducting two Monte Carlo simulations, sampling exclusively from variability distributions and sampling from both distribution types (ID 7). The impact of uncertainty and variability in method (ii) and (iii) is measured by how much the spread increases in the resulting probability distribution by also propagating variability and uncertainty respectively.

Basset-mens et al. (2009) (ID 1) highlighted the difficulty of defining appropriate probabilistic distributions for the input parameters. The lack of statistics for inventory data result in an additional and time-consuming phase for estimating their probabilistic functions based on a set of data, literature 
references or expert judgement. Moreover, the aggregated nature of available datasets make it difficult to define potential correlations between parameters (Yan and Boies, 2013).

The accuracy of Monte Carlo simulations output increases when more iterations are conducted (Hauschild et al., 2018; Igos et al., 2018). However, the number of iterations performed is generally stated as being a trade-off between acceptable accuracy and needed computation time (Chen and Corson, 2014; Hauschild et al., 2018; Igos et al., 2018). An insufficient amount of iterations will not give a reliable output, because the full range of possible input values will not be sampled from nor will the shape of the probability distribution be adequately represented. Yet, there is no specific amount of iterations that is generally large enough, rather it depends on when convergence is reached in the output of a specific model (Hauschild et al., 2018). Nevertheless, a rule of thumb of 10000 iterations is normally applied to ensure stable variance (Ciroth et al., 2004; Igos et al., 2018). Hauschild et al. (2018) suggest repeatedly increasing the number of iterations until the difference of two subsequent uncertainty measures (e.g., mean or standard deviation) is acceptably low [i.e., numerical stability is reached (US EPA Technical Panel, 1997)]. This is however also a subjective measure and the question then arises, what is "acceptably low"? Robust estimators (e.g., median or extreme percentiles) might produce an "acceptably low" difference with a lower increase in iterations. Though, since skewed distributions are commonly used in LCA (e.g., lognormal), solely using robust estimators should be avoided. This illustrates how the choice of number of iterations is practitionerspecific as well as study-specific (Hauschild et al., 2018).

In the selected studies, the number of iterations varied from 1000 to 50000 . One article (ID 2) did not mention the number of iterations that was used. Only two (ID 4 and 6) studies verified if increasing the number of iterations leads to an unacceptable difference compared to the smaller number. Steinmann et al. 2014) (ID 4) took a ten-fold of their chosen number of iterations (i.e., 10000 instead of 1000 runs) and concluded that the difference in uncertainty ratio (see section Statistical measure in 4.2.1) was smaller than 1\%. Chen and Corson 2014) (ID 6) specified that increasing their 1000 iterations to 5000 increased the computation time from 30 to 90 minutes for each farm, a difference considered unacceptable when compared to the corresponding increase in stability of estimates of the mean values.

In this context, it seems relevant to reflect on what a long computation time really looks like. Although computation time might appear long (say hours), it may in fact be relatively short compared to the time needed to complete, for example, the data inventory analysis. Hence, it seems unbalanced to limit computation time to hours, even days, given the importance of appropriate uncertainty and variability assessments. Lack of computational power and time should not be used to justify lack of convergence. For example, actual (super)computer capabilities exist able to solve thousands of parallel nonlinear differential equations for weather predictions. Therefore, the number of iterations 
should be increased accordingly to ensure that convergence is obtained (Hauschild et al., 2018). If needed, one can look for appropriate computational solutions at software or hardware level.

Monte Carlo simulations give a probability distribution as output, which might be challenging to disseminate to a broader audience. Communication can be simplified by using summary statistics or by taking specific values from the output distribution and using them to calculate a single value. Of the articles selected in this systematic review, Chen and Corson (2014) (ID 6) calculated coefficients of variations and Steinmann et al. (2014) (ID 4) and Hauck et al. (2014) (ID 5) calculated uncertainty and variability ratios to facilitate communication.

\section{Statistical measure: Coefficient of variation}

Chen and Corson (2014) (ID 6) conducted Monte Carlo simulations, only propagating uncertainty, for each individual life cycle and calculated the coefficients of variation for each life cycle as a measure for uncertainty. The degree of scatter among the calculated coefficients of variations reflect the interindividual variability in the coefficients of variations. Thus, the measure of variability is dependent on Monte Carlo simulations propagating uncertainty. It is difficult to conclude if either uncertainty or variability is dominating in the results, because two different, incomparable measuring systems (i.e. coefficient of variation and degree of scatter of individual life cycles) are used. Still, an indication is given by visualizing the strip plots (blue striped framed graph at the bottom left in fig. 5).

\section{Statistical measure: Uncertainty ratio $(\rho)$ and variability ratio $(r)$}

Steinmann et al. (2014) (ID 4) and Hauck et al. (2014) (ID 5) conducted Monte Carlo simulations, only propagating uncertainty, for each "individual" life cycle and for the "comprehensive" life cycle (encompassing all of the individual life cycles). They divided the $97.5^{\text {th }}$ percentile by the $2.5^{\text {th }}$ percentile, thereby creating an "uncertainty ratio" for the comprehensive life cycle. Steinman et al. (2014) (ID 4) also calculated that uncertainty ratio for each individual life cycle (see blue lines in the right blue striped framed graph in fig. 5). Subsequently, Steinman et al. (2014) (ID 4) and Hauck et al. (2014) (ID 5) calculated a "variability ratio" by dividing the $97.5^{\text {th }}$ percentile by the $2.5^{\text {th }}$ percentile of a set of arithmetic means taken from the resulting probability distributions that were generated by conducting Monte Carlo simulations for each individual life cycle (though both used median values in their graphical visualization instead of arithmetic means; see red line in blue striped framed graph in fig. 5). The uncertainty ratio and variability ratio show whether uncertainty or variability was the primary cause of the range in the results. If the ratio equals 1 , then the there is no effect upon the LCA results of uncertainty or variability respectively. If the uncertainty ratio is the biggest ratio, than further research may reduce the range in the LCA results. If the reverse is true, then further research will not substantially reduce the range, rather physical changes must occur, if possible (Steinmann et al., 2014). 
Only uncertainty and variability ratios make it possible for the reader to make a clear-cut conclusion regarding which is more dominating. Other methodologies are not as straightforward and can lead to more ambiguous conclusions [for example the incomparable measuring systems of Chen and Corson (2014) (ID 6)].

The variability ratio is based on an extensive database of deterministic values recorded for each included individual life cycle. Thus, calculating uncertainty and variability ratios is only possible if such widespread deterministic data is available for each individual life cycle. Moreover, Steinmann et al. (2014) (ID 4) pointed out that it was not always feasible to completely disentangle uncertainty and variability. They specified parameters as uncertain in their modeling approach, even though the influence of variability could not be fully excluded. However, even if they were able to completely distinguish between uncertainty and variability, their used methodology of calculating uncertainty and variability ratios does not seem to allow the presence of strictly variable parameters. Thus, even though variability and uncertainty ratios allow for a clear distinction and conclusion, it requires a high degree of quality of the data, which is often not available.

\subsubsection{Local sensitivity analysis}

ISO 14040/44 (2006a, 2006b) defines sensitivity analysis as: "systematic procedures for estimating the effects of the choices made regarding methods and data on the outcome of a study." However, sensitivity analysis is often used more broadly than how it is defined by ISO 14040/44 (2006a, 2006b). The sensitivity of a model also describes to which extent the variation of an input parameter leads to variation in the model result. Thus, a model is sensitive toward a parameter if a small change in the parameter results in a large change in the model result (Hauschild et al., 2018; Pianosi et al., 2016). A local sensitivity analysis can be considered as the effect of a certain predefined change in input on the output, while keeping the others constant (Björklund, 2002; Hauschild et al., 2018; Igos et al., 2018; Pianosi et al., 2016; Wolf et al., 2017).

\section{Scenario analysis}

Scenario analysis (first green visualization option in fig. 5) is a typical sensitivity analysis as defined by ISO 14040/44 (2006a, 2006b), where possible changes to the LCA results caused by discrete choices are calculated (Hauschild et al., 2018; Igos et al., 2018). In the selected studies, it was only used to evaluate uncertainty due to choices [i.e., allocation procedures (ID 3 and 7), functional units (ID 6), Life Cycle Inventory assumptions (ID 11) and Life Cycle Impact Assessment methods (ID 1, 4, 5 and 11)], temporal variability (ID 2, 4 and 10) and spatial variability (ID 4). Not one specific visualization option exists, rather the visualization is used to show the analysis results are repeated for each scenario. It is only feasible to maintain an overview when a limited amount of scenario's are being compared. Therefore, it is not an advisable method for considering parameter uncertainty and variability between sources and objects, because of their high amount of possible scenarios. 


\section{One-at-a-time approach}

Perturbation analysis with a one-at-a-time approach can be regarded as a local sensitivity analysis. Thus, interaction effects between parameters are ignored (Saltelli and Annoni, 2010). Groen et al. (2016b) mention two weaknesses associated with this method, i.e., the number of inputs parameters assessed is usually a subset of all input parameters and the arbitrary choice of the predefined change may not reflect the actual uncertainty range.

This last issue is somewhat countered to by the two articles (ID 4 and 10) that used perturbation analysis with a one-at-a-time approach in their study. Steinman et al. (2014) (ID 4) used sequential perturbation analysis to assess the sensitivity of the results with respect to the uncertain parameters (since only those can be reduced by additional research), using the $2.5^{\text {th }}$ and $97.5^{\text {th }}$ percentiles of the assigned probability distribution as a predefined change. Similarly, Clavreul et al. (2017) (ID 10) used the minimum and maximum values of the assigned probability distribution as a predefined change for their one-factor-at-a-time perturbation analysis. Results were visualized with error bars on a bar plot, showing the minimal and maximal results obtained when testing each parameter (ID 10) or with a tornado diagram (ID 4), where the longer bars at the top represent the parameters with the largest influence on the output (first two green graphs in fig. 5). Clavreul et al. (2017) (ID 10) underlined their primary data parameters (containing variability in farmer's input) in contrast with the secondary data parameters (classified as parameter uncertainty), in their bar plot allowing for a quick assessment for which the model output was most sensitive.

\section{Multiplier method}

Groen et al. (2016b) and Wolf et al. (2017) (ID 8 and 9) used the multiplier method (lowest green graph in fig. 5) as a local sensitivity analysis. The multiplier method uses first-order partial derivatives to quantify the effect of a small change around the default value of each input parameter on the result. The obtained multipliers can be interpreted as how much and in which direction a $1 \%$ increase in the input will affect the output (in \%) (Groen et al., 2016b; Wolf et al., 2017). Groen et al. (2016b) (ID 8) chose the multiplier method because it includes all input parameters, which is not necessarily the case in a one-at-a-time approach. Both studies (ID 8 and 9) distinguished in the inventory between uncertainty and variability, making it possible to assess if the biggest multipliers (in absolute values) correspond to either uncertain or variable parameters. The visualization of this multiplier method was done in a table (ID 8) or bar plot (ID 9) (last two green visualization options in fig. 5).

\subsubsection{Screening method}

\section{Method of elementary effects}

Next to the multiplier method, Groen et al. (2016b) (ID 8) also used the method of elementary effects, a kind of sensitivity analysis belonging to the area of screening methods (Igos et al., 2018; Saltelli et al., 2008). A screening method can be seen as an intermediate tool between local and global sensitivity 
analysis (see 4.2.2 and 4.2.4 respectively) to find approximate sensitivity information at a lower computational cost than global sensitivity analyses (Wei et al., 2015), and should be followed by a more detailed sensitivity analysis for the selected parameters (Mutel et al., 2013; Wei et al., 2015). The method is specifically convenient when there is a large number of parameters in the model (Saltelli et al., 2008). Local sensitivity analyses and screening methods can be used as a preliminary step to identify for which parameters the model is sensitive, and on which the focus should thus lie when gathering more representative data for more computationally intensive analyses [such as in Mutel et al. (2013)].

The method of elementary effects systematically varies all input parameters within their minimum and maximum values, instead of keeping all but one constant, to explore the full range of model outcomes (Igos et al., 2018; Mutel et al., 2013). Thus, the whole input space is explored rather than just a selection, as is the case in most local sensitivity analyses (Saltelli et al., 2008). It therefore gives more reliable and informative results than local sensitivity analyses (Igos et al., 2018). The method calculates for each input a number of incremental ratios, called "Elementary Effects", from which two sensitivity measures are computed i.e., the average and standard deviation (Campolongo et al., 2007). The average of an input's elementary effects reflects how sensitive the model is to that parameter, while the standard deviation is an indication for the interaction or non-linear effects within the model (Campolongo et al., 2007; Igos et al., 2018; Saltelli et al., 2008). Groen et al. (2016b) (ID 8) used the (absolute) mean of the average elementary effects [as refined by Campolongo et al. (2007)] to estimate the "importance" (see further) of a parameter, which they visualized in a bar plot (pink in fig. $5)$.

Generally speaking, while sensitivity analyses give information on the influence of a certain parameter on the result, an uncertainty analysis (including variability) shows how the spread in the input is reflected as spread in the output (Hauschild et al., 2018). It is possible that a highly uncertain input parameter has a negligible influence on the output uncertainty (i.e., the model output is insensitive to this parameter). Thus, changes within the uncertainty range will not lead to significant changes in the result, and improving the reliability of that parameter might therefore be redundant. Similarly, the fruitfulness of trying to improve the reliability of a very sensitive parameter is dependent on the degree of its certainty (Hauschild et al., 2018; Heijungs, 1996). Ideally, both types of information are studied to judge on which parameters the focus should lie.

Turning now to Groen et al. (2016b) (ID 8), these authors combined the results of the multiplier method $(|\eta|)$ and the (absolute) mean of the average elementary effects $\left(\mu^{*}\right)$ obtained by the method of elementary effects in a graph to identify their so called "essential" parameters (dark grey at the bottom right of fig. 5). This graph is adapted from Heijungs (1996), which distinguishes between data that is uncertain and data for which the final result is sensitive. The multipliers $(|\eta|)$ are ranked on the 
horizontal axis as "influence" [which Heijungs (1996) called "contribution" and Hauschild et al. (2018) called "sensitivity"], while the elementary effects $\left(\mu^{*}\right)$, defined as "importance", are ranked on the vertical axis [a.k.a. "uncertainty" (Hauschild et al., 2018; Heijungs, 1996)]. If a certain parameter ranks low for both sensitivity analyses, then those are defined as "minor parameters" [a.k.a. "not a key issue" (Heijungs, 1996) or "negligible parameters" (Hauschild et al., 2018)]. An "influential parameter" ranks low on the vertical axis and high on the horizontal axis [a.k.a. "perhaps a key issue" (Heijungs, 1996) or "possibly important parameter" (Hauschild et al., 2018)]. Those parameters could have the most impact if they are reduced (Groen et al., 2016b). An "important parameter" ranks high on the vertical axis and low on the horizontal axis [Heijungs (1996) and Hauschild et al. (2018) use the same terminology as for the "influential parameters"]. These are the most important parameters to the output uncertainty, caused by either variability or uncertainty (Groen et al., 2016b). Lastly, parameters that rank high on both axes (i.e., in the upper right corner) are defined as the "essential parameters" [a.k.a. "a key issue" (Heijungs, 1996) or "very important parameter" (Hauschild et al., 2018)], which can be used to identify mitigation strategies (Groen et al., 2016b).

By distinguishing between uncertain and variable parameters in the inventory phase, it is possible to identify if the mitigation strategies for the essential parameters should focus on e.g., improving reliability or adapting management strategies respectively (Groen et al., 2016b). Groen et al. (2016b) (ID 8) stated that the use of the method of elementary effects is limited because it is only based on minimum and maximum values, excluding a distribution function or an average value. They instead recommend using a global sensitivity analysis to rank the "importance" of a parameter, which was later done by Wolf et al. (2017) (ID 9).

\subsubsection{Global sensitivity analysis}

It is clear that Monte Carlo simulation is the preferred method for propagating uncertainty and variability in LCA, often in combination with a sensitivity analysis to quantify the contribution to variance of the input parameters. This is sometimes defined as global sensitivity analysis (Groen et al., 2016b; Igos et al., 2018; Wolf et al., 2017), which evaluates the sensitivity of the outputs to the variability and/or uncertainty of the entire input space (Igos et al., 2018; Pianosi et al., 2016). These more data-intensive global sensitivity methods are suitable to include correlations (Groen et al., 2016b).

Rank correlation and standardized regression coefficients

A simple global sensitivity analysis consists of a correlation analysis (i.e., calculating Spearman's rank correlation coefficients or regression coefficients) based on the sampled results from uncertainty propagation (e.g., Monte Carlo sampling) (Igos et al., 2018). Correlation methods use the correlation coefficient as a sensitivity measure, while regression analysis methods derive it as a 'byproduct' of regression analysis applied to the input/output sample, standardizing the regression coefficients when 
input factors have different units (Pianosi et al., 2016). Both methods include the effect of uncertainty and thus consider the range of variation of input parameters as a function of their uncertainty, varying them all at the same time (Hauschild et al., 2018). Therefore, contribution to variance combines the uncertainty range of the parameter and its model sensitivity (Basset-mens et al., 2009; Hauck et al., 2014). Thus, full knowledge of the input parameters is required (Wolf et al., 2017).

After conducting Monte Carlo simulations, Yan and Boies (2013) [ID 3; using Crystal Ball (Oracle, CA, USA)], Hauck et al. (2014) (ID 5; using Crystal Ball) and Chen and Corson (2014) [ID 6; using R (R Foundation for Statistical Computing, Vienna, Austria)] used Spearman rank correlation coefficients to assess the contribution to variance of each uncertain parameter (orange in fig. 5). The resulting statistics can be interpreted as the percentage of variance that may be explained by each uncertain input parameter (Hauck et al., 2014).

Alternatively, standardized regression coefficients can be calculated to assess the contribution to variance (orange in fig. 5), which was done by Zehetmeier et al. (2014) [ID 7; using @Risk (Palisade, NY, USA)] and Basset-mens et al. (2009) (ID 1; using @Risk). A regression coefficient predicts a standard deviation change in the output for one standard deviation change in the input parameter. Zehetmeier et al. (2014) (ID 7) expressed those coefficients in contribution percentages. Basset-mens et al. (2009) (ID 1) calculated regression coefficients for the uncertainty distributions and the variability distributions separately. Thus, they could assess if the key input parameters were ranked the same for both the "uncertainty" and "variability" analysis. Zehetmeier et al. (2014) (ID 7) calculated the regression coefficients based on the Monte Carlo sampling that was done when both uncertainty and variability were propagated alongside each other. Because they clearly showed which parameters had which type of uncertainty and/or variability in their inventory, the reader could decide which was dominating in the results based on their relative contribution to the variance.

\section{Statistical measure: Total sensitivity index}

Wolf et al. (2017) (ID 9) conducted Monte Carlo simulations, which they used to determine the output variance. Thereafter, they calculated the standardized regression coefficients (which they adjusted for correlated input parameters) to determine the parameters' contribution to the output variance, which they used as a proxy to calculate total sensitivity indices (orange striped framed graph in fig. 5). The sensitivity index represents the sensitivity of each input parameter and is given by a ratio explaining how much each input parameter contributes to the output variance (Groen and Heijungs, 2017).

Wolf et al. (2017) (ID 9) used the same graphical visualization as Groen et al. (2016b) (ID 8). However, instead of using the vertical axis to show elementary effects, they identified their "important" parameters by using the total sensitivity indices ( $\hat{\mathrm{S}}_{\mathrm{T}}$; dark grey in fig. 5). Thus, their "essential" parameters have a big multiplier and a high total sensitivity index. Because Wolf et al. (2017) strictly distinguished in the inventory between uncertain and variable parameters, it was 
possible to assess if the most important or essential parameters are affected by either uncertainty or variability.

Identifying the essential parameters through the use of the multiplier method and sensitivity indices is a methodologically sound and visually appealing way to analyze uncertain and variable parameters separately, but evidently it is only possible if there is a clear distinction made in the inventory phase. The sensitivity indices do not necessarily have to be derived from standardized regression coefficients. According to Groen et al. (2016a) the sampling-based methods squared Spearman correlation coefficients and Sobol's indices (Sobol, 2001) or the analytical method key issue analysis (Heijungs, 1996) can also be used for global sensitivity analysis in LCA, in which case the choice depends on the available data, the magnitude of its' uncertainties and the aim of the study.

\section{Conclusions and recommendations}

A first observation made during the preparatory phase of this research is that even in this era, no consensus on definitions and viewpoints on the terms uncertainty and variability could be found in the selected articles. Classification of the different types of uncertainty and variability clearly depended on the Goal \& Scope Definition and on the quality of the data, and was on some occasions open for interpretation. Regardless, the most important thing is that uncertainty and variability are both considered and propagated in some way. While some studies really focused on separating uncertainty and variability, with others it seemed more coincidental or as an after-thought. Properly accounting for and dealing with uncertainty and variability should be a part of the LCA process from the very start.

A large number of studies combine a variety of methodologies to propagate and analyze uncertainty and variability through the different LCA phases, often following a multi-step approach as described by Igos et al. (2018). Based on the used methodologies in the included articles, the different steps for the treatment of uncertainty and variability (Igos et al., 2018) can be categorized as follows: (i) characterization using multiple scenario's, predefined changes, ranges around a default value or probability distributions, (ii) uncertainty and variability propagation using Monte Carlo simulations; (iii-a) local sensitivity analysis using scenario analysis, one-at-a-time approach or the multiplier method; (iii-b) screening method using the method of elementary effects; or (iii-c) global sensitivity analysis by calculating rank correlation coefficients or regression coefficients; and (iv) visualization using summary statistics, ranges, coefficients of variation, uncertainty and variability ratios, contribution to variance percentages, sensitivity indices and essential (i.e., both important and influential) parameters.

Regarding characterization, the challenge lies in representing the uncertain and variable data as realistically as possible. It is essential that uncertainty and variability are already sufficiently taken 
into consideration during the inventory phase, and not just as an after-thought once the assessment has been completed. While defining multiple scenarios can be effective for a limited number of scenarios, a clear overview can be lost quickly when that number increases. Moreover, a range around a default value can be useful to get a first impression of the results and to identify where the focus should lie. Still, using probability distributions is the most preferable of the four characterization options used in the included articles. Although it requires much effort and time to gather the required input information, rich information is returned, including the possibility to reflect correlations. Local sensitivity analyses and screening methods can be used as a preliminary step to identify the most influential parameters on which the focus should lie for gathering more data for further analyses.

Regarding uncertainty and variability propagation, only the Monte Carlo method - a sampling method - was used in the selected articles of the systematic review. Monte Carlo simulation outputs - where either uncertainty, variability or both are propagated - can be used to conclude if either uncertainty or variability is dominating in the results. Output probability distributions and their statistics can be visualized and compared. However, each uncertain and/or variable input parameter should then have an appropriate probability distribution assigned to it during the inventory phase. It is advisable to combine uncertainty analysis with a sensitivity analysis. Sensitivity analysis can be used after the uncertainty and variability propagation to determine how much influence the highly uncertain parameters have, and thus where uncertainty reduction is most desirable.

In contrast, global sensitivity analysis is more of an extension of an uncertainty analysis. Hence, the conclusion of which is dominating can also be based on a global sensitivity analysis in combination with a local sensitivity analysis. Measures of sensitivity can be visualized and compared by clearly showing which input parameter is uncertain and which is variable. Thus, this method also requires a clear distinction to be made between uncertainty and variability in the inventory phase. Predefined changes, uncertainty ranges or probability distributions for Monte Carlo sampling need to be defined for each uncertain and/or variable input parameter.

Based on the methodologies used by the eleven selected articles and keeping the need for clear communication in mind, we strongly recommend Monte Carlo simulations visualized in (i) uncertainty and variability ratios and/or (ii) total sensitivity indices through global sensitivity analysis for future use in LCA. On one hand, ratios allow to clearly decide whether uncertainty or variability is most dominating. The two ratios are clearly separated from each other, they can be easily compared because the outcome is a single value, and they are calculated based on probability output distributions from Monte Carlo simulations, making them representative towards the reality. On the other hand, total sensitivity indices (or another suitable index calculated by global sensitivity analysis) in combination with the results of a local sensitivity analysis (such as the multiplier method), allow to identify the essential parameters and whether these are predominantly uncertain or variable. 
Combining uncertainty/variability and sensitivity measures allows for a clear communication to the actors on which parameters the focus should lie in further decision making regarding e.g., uncertainty reduction and system improvement. Depending on the goal and scope of the LCA study, either methodology can be a good option, provided that the outcomes are interpreted within the studyspecific choices made during classification.

\section{Acknowledgements}

The authors wish to thank the information specialists of the KU Leuven Libraries - 2Bergen Academic services - (Leuven, Belgium) for their help in conducting the systematic literature search. The authors would also like to acknowledge the KU Leuven, Department of Biosystems (BIOSYST) for financing the $\mathrm{PhD}$ scholarship of the first author.

\section{References}

AzariJafari, H., Yahia, A., Amor, B., 2018. Assessing the individual and combined effects of uncertainty and variability sources in comparative LCA of pavements. Int. J. Life Cycle Assess. 23, 1888-1902. https://doi.org/10.1007/s11367-017-1400-1

BASF, 2018. Quantifying Sustainability [WWW Document]. URL

https://www.basf.com/en/company/sustainability/management-and-instruments/quantifyingsustainability.html (accessed 11.23.18).

Basset-mens, C., Kelliher, F.M., Ledgard, S., Cox, N., 2009. Uncertainty of global warming potential for milk production on a New Zealand farm and implications for decision making. Int. J. Life Cycle Assess. 14, 630-638. https://doi.org/10.1007/s11367-009-0108-2

Bautista, R., Thoma, G., Ulrich, R., Matlock, M.D., Leh, M., Bandekar, P.A., 2018. Life cycle assessment of alternative swine management practices. J. Anim. Sci. 97, 472-484. https://doi.org/10.1093/jas/sky425

Björklund, A.E., 2002. Survey of approaches to improve reliability in lca. Int. J. Life Cycle Assess. 7, 64-72. https://doi.org/10.1007/BF02978849

Bosona, T., Gebresenbet, G., 2018. Life cycle analysis of organic tomato production and supply in Sweden. J. Clean. Prod. 196, 635-643. https://doi.org/10.1016/j.jclepro.2018.06.087

Campolongo, F., Cariboni, J., Saltelli, A., 2007. An effective screening design for sensitivity analysis of large models. Environ. Model. Softw. 22, 1509-1518. https://doi.org/10.1016/j.envsoft.2006.10.004

Chen, X., Corson, M.S., 2014. Influence of emission-factor uncertainty and farm-characteristic variability in LCA estimates of environmental impacts of French dairy farms. J. Clean. Prod. 81, 150-157. https://doi.org/10.1016/j.jclepro.2014.06.046

Ciroth, A., Fleischer, G., Steinbach, J., 2004. Uncertainty Calculation in Life Cycle Assessments: A Combined Model of Simulation and Approximation. Int. J. Life Cycle Assess. 9, 216-226. 
https://doi.org/10.1065/lca2004.05.158

Clavreul, J., Butnar, I., Rubio, V., King, H., 2017. Intra- and inter-year variability of agricultural carbon footprints - A case study on field-grown tomatoes. J. Clean. Prod. 158, 156-164. https://doi.org/10.1016/j.jclepro.2017.05.004

European Commission, 2018. PEFCR Guidance document - Guidance for the development of Product Environmental Footprint Category Rules (PEFCRs), version 6.3.

Goossens, Y., Annaert, B., De Tavernier, J., Mathijs, E., Keulemans, W., Geeraerd, A., 2017. Life cycle assessment (LCA) for apple orchard production systems including low and high productive years in conventional, integrated and organic farms. Agric. Syst. 153, 81-93. https://doi.org/10.1016/j.agsy.2017.01.007

Groen, E.A., Bokkers, E.A.M., Heijungs, R., de Boer, I.J.M., 2016a. Methods for global sensitivity analysis in life cycle assessment. Int. J. Life Cycle Assess. 1125-1137. https://doi.org/10.1007/s11367-016-1217-3

Groen, E.A., Heijungs, R., 2017. Ignoring correlation in uncertainty and sensitivity analysis in life cycle assessment: what is the risk? Environ. Impact Assess. Rev. 62, 98-109. https://doi.org/10.1016/j.eiar.2016.10.006

Groen, E.A., Heijungs, R., Bokkers, E.A.M., de Boer, I.J.M., 2014. Methods for uncertainty propagation in life cycle assessment. Environ. Model. Softw. 62, 316-325. https://doi.org/10.1016/j.envsoft.2014.10.006

Groen, E.A., van Zanten, H.H.E., Heijungs, R., Bokkers, E.A.M., de Boer, I.J.M., 2016b. Sensitivity analysis of greenhouse gas emissions from a pork production chain. J. Clean. Prod. 129, 202-211. https://doi.org/10.1016/j.jclepro.2016.04.081

Hajibabaei, M., Nazif, S., Tavanaei Sereshgi, F., 2018. Life cycle assessment of pipes and piping process in drinking water distribution networks to reduce environmental impact. Sustain. Cities Soc. 43, 538-549. https://doi.org/10.1016/j.scs.2018.09.014

Hauck, M., Steinmann, Z.J.N., Laurenzi, I.J., Karuppiah, R., Huijbregts, M.A.J., 2014. How to quantify uncertainty and variability in life cycle assessment: the case of greenhouse gas emissions of gas power generation in the US. Environ. Res. Lett. 9, 074005. https://doi.org/10.1088/1748-9326/9/7/074005

Hauschild, M., Rosenbaum, R.K., Olsen, S.I., Al., E., 2018. Life Cycle Assessment - Theory and Practice. Springer International Publishing. https://doi.org/10.1007/978-3-319-56475-3

Heijungs, R., 1996. Identification of key issues for further investigation in improving the reliability of life-cycle assessments. J. Clean. Prod. 4, 159-166. https://doi.org/10.1016/S0959-6526(96)00042-X

Heijungs, R., Huijbregts, M.A.J., 2004. A Review of Approaches to Treat Uncertainty in LCA, in: International Congress on Environmental Modelling and Software. p. 9 pp.

Heijungs, R., Lenzen, M., 2014. Error propagation methods for LCA - A comparison. Int. J. Life Cycle Assess. 19, 1445-1461. https://doi.org/10.1007/s11367-014-0751-0 
Huijbregts, M.A.J., 1998. Application of uncertainty and variability in LCA - Part I : A General Framework for the Analysis of Uncertainty and Variability in Life Cycle Assessment. Int. J. Life Cycle Assess. 3, 273280. https://doi.org/10.1007/BF02979835

Igos, E., Benetto, E., Meyer, R., Baustert, P., Othoniel, B., 2018. How to treat uncertainties in life cycle assessment studies? Int. J. Life Cycle Assess. 1-14. https://doi.org/10.1007/s11367-018-1477-1

ISO, 2006a. Environmental management — Life cycle assessment — Requirements and guidelines, ISO 14044:2006(E).

ISO, 2006b. Environmental management — Life cycle assessment — Principles and framework, ISO 14040:2006(E). https://doi.org/10.1136/bmj.332.7550.1107

Jiao, J., Li, J., Bai, Y., 2019. Uncertainty analysis in the life cycle assessment of cassava ethanol in China. J. Clean. Prod. 206, 438-451. https://doi.org/10.1016/j.jclepro.2018.09.199

Lloyd, S.M., Ries, R., 2007. Characterizing, propagating, and analyzing uncertainty in life-cycle assessment. J. Ind. Ecol. 11, 161-181. https://doi.org/10.1162/jiec.2007.1136

Milà i Canals, L., Azapagic, A., Doka, G., Jefferies, D., King, H., Mutel, C., Nemecek, T., Roches, A., Sim, S., Stichnothe, H., Thoma, G., Williams, A., i Canals, L., Azapagic, A., Doka, G., Jefferies, D., King, H., Mutel, C., Nemecek, T., Roches, A., Sim, S., Stichnothe, H., Thoma, G., Williams, A., 2011. Approaches for addressing life cycle assessment data gaps for bio-based products. J. Ind. Ecol. 15, 707-725. https://doi.org/10.1111/j.1530-9290.2011.00369.x

Moher, D., Liberati, A., Tetzlaff, J., Altman, D.G., 2009. Preferred Reporting Items for Systematic Reviews and Meta-Analyses: The PRISMA Statement. Ann. Intern. Med. 151, 264-269. https://doi.org/10.1371/journal.pmed1000097

Mutel, C.L., de Baan, L., Hellweg, S., 2013. Two-Step Sensitivity Testing of Parametrized and Regionalized Life Cycle Assessments: Methodology and Case Study. Environ. Sci. Technol. 47, 5660-5667. https://doi.org/10.1021/es3050949

Notarnicola, B., Sala, S., Antón, A., McLaren, S.J., Saouter, E., Sonesson, U., 2017. The role of life cycle assessment in supporting sustainable agri-food systems: A review of the challenges. J. Clean. Prod. 140, 399-409. https://doi.org/10.1016/j.jclepro.2016.06.071

Pianosi, F., Beven, K., Freer, J., Hall, J.W., Rougier, J., Stephenson, D.B., Wagener, T., 2016. Sensitivity analysis of environmental models: A systematic review with practical workflow. Environ. Model. Softw. 79, 214-232. https://doi.org/10.1016/j.envsoft.2016.02.008

Röös, E., Sundberg, C., Hansson, P.-A., 2011. Uncertainties in the carbon footprint of refined wheat products: a case study on Swedish pasta. Int. J. Life Cycle Assess. 16, 338-350. https://doi.org/10.1007/s11367-0110270-1

Saltelli, A., Aleksankina, K., Becker, W., Fennell, P., Ferretti, F., Holst, N., Li, S., Wu, Q., 2019. Why so many published sensitivity analyses are false: A systematic review of sensitivity analysis practices. Environ. 
Model. Softw. 114, 29-39. https://doi.org/10.1016/j.envsoft.2019.01.012

Saltelli, A., Annoni, P., 2010. How to avoid a perfunctory sensitivity analysis. Environ. Model. Softw. 25, 1508-1517. https://doi.org/10.1016/j.envsoft.2010.04.012

Saltelli, A., Ratto, M., Andres, T., Campolongo, F., Cariboni, J., Gatelli, D., Saisana, M., Tarantola, S., 2008. Global Sensitivity Analysis. The Primer. John Wiley \& Sons, Ltd, West Sussex, England. https://doi.org/10.1002/9780470725184

Sastre, C.M., González-Arechavala, Y., Santos, A.M., 2015. Global warming and energy yield evaluation of Spanish wheat straw electricity generation - A LCA that takes into account parameter uncertainty and variability. Appl. Energy 154, 900-911. https://doi.org/10.1016/j.apenergy.2015.05.108

Sobol, I.M., 2001. Global sensitivity indices for nonlinear mathematical models and their Monte Carlo estimates. Math. Comput. Simul. 55, 271-280. https://doi.org/10.1016/S0378-4754(00)00270-6

Steinmann, Z.J.N., Hauck, M., Karuppiah, R., Laurenzi, I.J., Huijbregts, M.A.J., 2014. A methodology for separating uncertainty and variability in the life cycle greenhouse gas emissions of coal-fueled power generation in the USA. Int. J. Life Cycle Assess. 19, 1146-1155. https://doi.org/10.1007/s11367-0140717-2

Tan, R.R., 2008. Using fuzzy numbers to propagate uncertainty in matrix-based LCI. Int. J. Life Cycle Assess. 13, 585-592. https://doi.org/10.1007/s11367-008-0032-x

Unilever, 2018. Reducing environmental impact [WWW Document]. URL https://www.unilever.com/sustainable-living/reducing-environmental-impact/ (accessed 11.23.18).

US EPA Technical Panel, 1997. Guiding Principles for Monte Carlo Analysis, Us Epa. Washington, DC. https://doi.org/EPA/630/R-97/001

van der Werf, H.M.G., Kanyarushoki, C., Corson, M.S., 2009. An operational method for the evaluation of resource use and environmental impacts of dairy farms by life cycle assessment. J. Environ. Manage. 90, 3643-3652. https://doi.org/10.1016/j.jenvman.2009.07.003

Venkatesh, A., Jaramillo, P., Griffin, W.M., Matthews, H.S., 2011. Uncertainty in Life Cycle Greenhouse Gas Emissions from United States Natural Gas End-Uses and its Effects on Policy. Environ. Sci. Technol. 45, 8182-8189. https://doi.org/10.1021/es200930h

Walker, W.E., Herremoës, P., Van Der Sluijs, J.P., Van Asselt, M.B.A., Janssen, P., Krayer Von Krauss, M.P., 2003. Defining Uncertainty: A Conceptual Basis for Uncertainty Management in Model-Based Decision Support. Integr. Assess. 13 pp.

Warmink, J.J., Janssen, J.A.E.B., Booij, M.J., Krol, M.S., 2010. Identification and classification of uncertainties in the application of environmental models. Environ. Model. Softw. 25, 1518-1527. https://doi.org/10.1016/j.envsoft.2010.04.011

Wei, W., Larrey-Lassalle, P., Faure, T., Dumoulin, N., Roux, P., Mathias, J.D., 2015. How to conduct a proper 
sensitivity analysis in life cycle assessment: Taking into account correlations within LCI data and interactions within the LCA calculation model. Environ. Sci. Technol. 49, 377-385.

https://doi.org/10.1021/es502128k

Wolf, P., Groen, E.A., Berg, W., Prochnow, A., Bokkers, E.A.M., Heijungs, R., de Boer, I.J.M., 2017.

Assessing greenhouse gas emissions of milk production: which parameters are essential? Int. J. Life Cycle Assess. 22, 441-455. https://doi.org/10.1007/s11367-016-1165-y

Wood, P., Phillips, L., Adenuga, A., Koontz, M., Rector, H., Wilkes, C., Wilson, M., 1997. Exposure Factors Hanbook. U.S. Environmental Protection Agency. https://doi.org/EPA/600/P-95/002F a-c,

Yan, X., Boies, A.M., 2013. Quantifying the uncertainties in life cycle greenhouse gas emissions for UK wheat ethanol. Environ. Res. Lett. 8, 12. https://doi.org/10.1088/1748-9326/8/1/015024

Zehetmeier, M., Gandorfer, M., Hoffmann, H., Mueller, U.K., de Boer, I.J.M., Heissenhuber, A., 2014. The impact of uncertainties on predicted greenhouse gas emissions of dairy cow production systems. J. Clean. Prod. 73, 116-124. https://doi.org/10.1016/j.jclepro.2013.09.054 


\section{Electronic supplementary material caption}

2 ESM_1Full-text eligibility check which indicates for which of the three possible reasons the selected

3 articles were excluded (only one is indicated, however they are not mutually exclusive): (i) the article

4 does not mention the distinction between uncertainty and variability, or only in passing, (ii) the article

5 does not take both 'parameter uncertainty' and 'variability between sources and objects' into

6 consideration, and (iii) it cannot be concluded if either uncertainty or variability is dominating 